\title{
Análisis jurisprudencial: el gravamen de dividendos en el impuesto de industria y comercio
}

\section{Jurisprudential Analysis: The taxation of dividends in the Industry and Commerce Tax}

\section{Análise Jurisprudencial: A tributação de dividendos no Imposto sobre Indústria e Comércio}

Rossana Galeano Gómez 


\title{
Resumen
}

El impuesto de industria y comercio ha existido en Colombia desde 1983 y, desde esta época, ha sido objeto de demandas y conflictos en el Consejo de Estado. Una de las principales discusiones ha sido la consideración de los dividendos y las rentas pasivas como activos objeto de gravamen por parte del Estado. Las consideraciones de por qué deben o no ser gravadas por el impuesto pasan a ser estudiadas de manera amplia observando en cada caso las diferentes sentencias que se consideraron con un valor y tema relevante para la tesis analizada de si se debían entender como gravados los dividendos en el impuesto de industria y comercio en Colombia.

Palabras clave: impuesto de industria y comercio; gravamen de dividendos; análisis jurisprudencial; Consejo de Estado.

\begin{abstract}
The industry and commerce tax has existed in Colombia since 1983 and since this time it has been the subject of lawsuits and conflicts in the State Council. One of the main discussions that have been held since this beginning has been the consideration of dividends and passive income as assets subject to taxation by the State. The considerations of why they should or should not be taxed go to be studied in a broad way observing in each case the different sentences that were considered with a value and topic relevant to the thesis that we wanted to analyze if they should be understood as taxed dividends in the industry and commerce tax in Colombia.
\end{abstract}

Key words: Industry and commerce tax; dividend tax; jurisprudential analysis; Consejo de Estado.

\section{Resumo}

O imposto sobre a indústria e o comércio existe na Colômbia desde 1983 e, desde então, é objeto de ações e conflitos no Conselho de Estado. Uma das principais discussões realizadas desde esse início tem sido a consideração de dividendos e receita passiva como ativos sujeitos a tributação pelo Estado. As considerações sobre por que eles deveriam ou não ser tributados passam a ser estudadas de maneira ampla, observando em cada caso as diferentes frases que foram consideradas com um valor e tópico relevante para a tese que queríamos analisar se elas deveriam ser entendidas como tributadas. dividendos no imposto industrial e comercial na Colômbia.

Palavras-chave: Imposto sobre indústria e comércio; imposto sobre dividendos; análise jurisprudencial; Conselho de Estado. 


\section{Introducción}

El presente trabajo se centrará en el análisis jurisprudencial del impuesto de industria y comercio, específicamente en los ingresos obtenidos por concepto de dividendos. A lo largo de los años, este concepto de ingresos ha llevado a discusiones legislativas, administrativas y jurisprudenciales, las cuales han permitido que el impuesto crezca y se desarrolle, pero aun así deja abiertos litigios e inseguridad jurídica. En efecto, este desarrollo no puede ser entendido como claro y constante en algunos aspectos del impuesto, como son los ingresos por concepto de dividendos.

Los ingresos por concepto de dividendos han creado diferencias entre la administración y el contribuyente, que han debido ser resueltas por el Consejo de Estado dada la falta de acuerdo que se ha presentado entre las entidades y los contribuyentes. El conflicto por la noción de dividendos se centra en la falta de evidencia de estos como un concepto gravado en el impuesto. A pesar de que se han dado indicios o se pueden hacer analogías y extrapolar conceptos que lo consideren un elemento gravado, no es posible tener una completa certeza o un gravamen explícito del ingreso.

Debido a esta falta de certeza se ha creado una jurisprudencia amplia y variada en el Consejo de Estado que, más que dar claridad total al asunto, ha permitido que se manejen consideraciones varias, así como indicios para ser tomados en cuenta por la administración, a fin de entender cuándo un ingreso por concepto de dividendos debe o no ser gravado.

\section{El impuesto de industria y comercio}

El de industria y comercio es el impuesto municipal por medio del cual se grava el desarrollo de actividades comerciales, industriales y de servicios en los municipios de Colombia. Fue introducido al ordenamiento tributario para el Distrito de Bogotá bajo la Ley 97 de 1913 y, posteriormente, desarrollado por la Ley 14 de 1983 (Piza, 2017, p. 136).

Durante todos estos años, como era de esperarse, el impuesto ha venido sufriendo modificaciones de acuerdo con los desarrollos sociales, las nuevas tendencias comerciales y el surgimiento de nuevas actividades económicas para ser gravadas por él. Dado su carácter municipal, se permite que los municipios expidan excepciones dentro de sus estatutos de renta, o graven de acuerdo con un parámetro de tarifas, las actividades establecidas en el decreto, según sus necesidades, incluyéndose como un nuevo sujeto de modificación en el impuesto.

El impuesto de industria y comercio se encuentra regulado en sus aspectos primordiales en la Ley 14 de 1983, en los artículos 32 al 40; igualmente, cada municipio adapta el impuesto en sus estatutos municipales. Los artículos establecen los elementos necesarios para la formulación de un impuesto. Es importante aclarar, sin embargo, que, dada la condición de territorialidad del impuesto, se permitió el libre establecimiento de condiciones adicionales por parte de los municipios, siempre que estas no fueran en contra de 
lo establecido en la ley y los decretos reglamentarios nacionales posteriores que regulan el impuesto. Esto permitió que los municipios contaran con una cierta libertad en su control y recaudo, así como la exención o el cobro a las actividades que consideraban necesarias.

En el caso de la base gravable, por ejemplo, es clara la influencia del estatuto de Bogotá al ser transcrito el concepto de base gravable del impuesto de industria y comercio, el cual se encuentra plasmado en la legislación nacional. La nueva definición permite establecer que la base gravable del impuesto será entendida bajo "la totalidad de los ingresos ordinarios y extraordinarios percibidos en el respectivo año gravable, incluidos los ingresos obtenidos por rendimientos financieros, comisiones y, en general, todos los que no estén expresamente excluidos en este artículo" (Ley 1819 de 2016, art. 343). El cambio genera un fuerte impacto, pues la base gravable es mucho más amplia e indeterminada en el estatuto de Bogotá, en contraste con lo contemplado en la ley anterior, la cual señalaba: "El impuesto de industria y comercio se liquidará sobre el promedio mensual de ingresos brutos del año inmediatamente anterior, expresados en moneda nacional y obtenidos por las personas y sociedades de hecho indicadas en el artículo anterior"1 (Ley 14 de 1983, art. 33), lo que limitaba ampliamente la base a únicamente los ingresos obtenidos por la sociedad o el sujeto. La amplitud de los nuevos ingresos de la base gravable genera indeterminación y duda en los contribuyentes.

A pesar de que el impuesto se encuentra limitado con anterioridad, se han dado diferentes líneas de división de la territorialidad con el fin de tener claro el lugar correspondiente a los ingresos por el gravamen. Estas diferencias han sido establecidas para evitar conflictos entre los territorios. Muchas de estas líneas de diferencia se plantearon en el artículo 343 de la Ley 1819 de 2016.

Para el caso de estudio es importante especialmente el inciso d) del artículo 343: “d) En la actividad de inversionistas, los ingresos se entienden gravados en el municipio o distrito donde se encuentra ubicada la sede de la sociedad donde se poseen las inversiones".

Dada la necesidad de tener una conexidad entre las actividades de inversión y rendimiento financiero, con las actividades comerciales y los actos de comercio en los que se encuentran encausados, es inusual que se amplíe la actividad inversora y sea este el término utilizado. La actividad de inversión se encuentra establecida en el artículo 20 del Código de Comercio (CC), cuando se refiere a las actividades mercantiles como aquellas de negocio y negociación onerosa de las partes y las acciones. La inversión es ejemplo de esta negociación cuando es entendida desde un punto de vista comercial organizado. Como lo ha demostrado en su libro Parra Ortiz (2004), de la combinación presente en las actividades de comercio y mercantiles, así como de las condiciones de la persona que ejecuta la actividad de inversión, "los rendimientos financieros conforman la base gravable, siempre y cuando los mismos se obtengan como consecuencia del ejercicio de una actividad gravada, es decir de una actividad comercial".

$1 \quad$ El artículo 33 de la Ley 14 de 1983 que se muestra en este caso es la redacción del Decreto 1333 de 1996, artículo 196, el cual modifica el artículo 33 de la Ley 14 de 1983. 
En esa dirección, todas las actividades que puedan ser tomadas como inversión están obligadas a pagar impuesto de industria y comercio. El conflicto se acentúa debido a que, en este tipo de actividades, se ha entendido que en la doctrina solo serán gravables cuando se encuentren bajo el marco de una actividad comercial, realizada por personas definidas como comerciantes. El concepto de comerciantes y personas que realicen actos comerciales será estudiado más adelante, para poder entender con mayor claridad y profundidad sus ramificaciones. Sin embargo, sí es posible decir en este caso que las actividades de comerciante influirán sobre terceros que no realicen una inversión u obtengan un rendimiento financiero como parte de su negocio, sino como una consecuencia; ejemplo de ello son los rendimientos por una cuenta de ahorros o corrientes (Parra Ortiz, 2004). En este caso consideramos que no puede entenderse que existe una conexidad necesaria para que se tenga como obligatorio el cobro de las actividades de inversión en su condición de actividades genéricas realizadas en cualquier momento, con o sin ánimo de obtener un ingreso, con ánimo de lucro personal.

En vista de lo anterior, procederemos a describir el impuesto de industria y comercio, en tanto que su normativa influye en la incertidumbre y la problemática de cuándo debe o no ser entendido como gravado el ingreso por concepto de dividendos.

\section{A. Hecho generador}

El hecho generador se refiere a los preceptos legales y normativos que han sido fijados en la ley y que conllevan la obligación. Puede entenderse, entonces, que el hecho generador son los presupuestos fácticos establecidos para que se pueda configurar la opción de cobro del impuesto. Así lo indica Mauricio Marín: “el hecho generador es una creación legal, para la que se toma un objeto de la realidad, y a partir de él, se describen situaciones cuya realización determina el nacimiento de la obligación tributaria” (2017).

En el impuesto de industria y comercio, el hecho generador se encuentra establecido en la Ley 14 de 1983, artículo 32.

Artículo 32. El Impuesto de Industria y comercio recaerá, en cuanto a materia imponible, sobre todas las actividades comerciales, industriales y de servicio que ejerzan o realicen en las respectivas jurisdicciones municipales, directa o indirectamente, por personas naturales, jurídicas o por sociedades de hecho, ya sea que se cumplan en forma permanente u ocasional, en inmuebles determinados, con establecimientos de comercio o sin ellos.

\section{B. Elemento subjetivo}

\section{El SUJETO ACTIVO}

En este impuesto el sujeto activo es el Estado. El impuesto de industria y comercio, sin embargo, es un impuesto de carácter municipal, por lo que es recaudado y utilizado por cada uno de los municipios. 


\section{El SUJETO PASIVO}

El sujeto pasivo del impuesto de industria y comercio es bastante amplio, como se puede evidenciar en el artículo 32 de la Ley 14 de 1983. El aparte más importante de este sujeto, en el hecho generador, señala:

El Impuesto de Industria y comercio recaerá, [...] en cuanto a materia imponible, sobre todas las actividades comerciales, industriales y de servicio que ejerzan o realicen en las respectivas jurisdicciones municipales, directa o indirectamente, por personas naturales, jurídicas o por sociedades de hecho, ya sea que se cumplan en forma permanente u ocasional, en inmuebles determinados, con establecimientos de comercio o sin ellos. (Énfasis agregado)

\section{Elemento objetivo}

\section{ASPECTO MATERIAL}

El aspecto material del impuesto se basa en las consideraciones gravables y la materia imponible sobre la que recae el impuesto. Podemos ver, en primer lugar, las actividades que la ley entiende desarrollan el impuesto. Es decir, son las actividades que, al ser realizadas por los sujetos pasivos darán pie a una actividad imponible gravada. Dichas actividades son las de servicios, industriales y mercantiles. Estas actividades marcan los parámetros de desarrollo de las personas naturales o jurídicas sobre las que se desarrollarán, e igualmente obtendrán los ingresos sobre los que se gravará el impuesto de industria y comercio. Se encuentran desarrolladas de manera más amplia en el artículo 34, respecto a las actividades industriales; el artículo 35, sobre las actividades comerciales y el artículo 36, respecto de las actividades de servicio de la Ley 14 de 1983. El desarrollo de actividades establecidas en la ley, de manera declarativa, permite que se puedan incluir dentro del concepto las actividades afines o análogas.

Dado que la problemática por tratar en este caso es el manejo de los ingresos por concepto de dividendos como ingresos gravados o no, por el impuesto de industria y comercio, es esta actividad la que encierra los procesos de acciones y dividendos que guían el análisis. La actividad comercial se presenta en los casos en los que se da "la negociación a título oneroso de las partes de interés, cuotas o acciones" (art. 20, CC).

Las actividades de comercio se relacionan en los aspectos materiales de la ley comercial y se entrecruzan para dar significado completo a la normativa de estas. Más adelante se revisará la forma como es entendido este artículo, así como la explicación del aspecto material del impuesto de industria y comercio. En este mismo sentido, se analizarán las normas tributarias que no se encuentran relacionadas en la Ley 14 de 1983.

Las actividades comerciales son "las destinadas al expendio, compraventa, o distribución de bienes o mercancías, tanto al por mayor como al por menor, y las demás definidas 
como tales por el Código de Comercio, siempre y cuando no estén consideradas por el mismo Código o por esta Ley, como actividades industriales o de servicios" (Ley 14 de 1983, art. 33). Dichas actividades se encuentran relacionadas con aquellas citadas en la ley como actividades comerciales. Es evidente que se refiere a las de expendio y, en general, las más aproximadas a los servicios de compra y venta de los servicios comerciales básicos del hecho.

\section{- Actividades comerciales}

\section{- Las actividades comerciales según el Código de Comercio}

La Ley 14 de 1983 señala que las actividades comerciales serán las indicadas en el Código de Comercio, mientras no se contrapongan a las que se tiene en la ley. Dado que las establecidas en la ley no constituyen una actividad que genere dudas o contradicciones, nos centraremos en las actividades que describe el Código de Comercio como comerciales. Las establecidas por la ley y el código incluyen un repertorio amplio de actividades, en general no descritas de manera tacita, sino con lineamientos que se entienden como actividad comercial. Realizar, entonces, un análisis de todas las actividades del código nos desviaría del problema del trabajo; por tanto, nos concentraremos en las actividades comerciales que desarrollan los dividendos. Justamente, en el numeral 5 del artículo 20 se menciona: "Son mercantiles para todos los efectos legales: 5) La intervención como asociado en la constitución de sociedades comerciales, los actos de administración de estas o la negociación a título oneroso de las partes de interés, cuotas o acciones".

En este caso, la actividad comercial es la negociación onerosa de acciones. En el momento en el que se realice, por parte de una persona natural, la negociación de acciones a título oneroso deberá considerarse que realiza una actividad comercial de acuerdo con lo establecido por el Código de Comercio y sobre la base de la Ley 14 de 1983. Puede que la posesión de acciones que generen ingresos por dividendos a las personas, constituya una obligación de pago del impuesto de industria y comercio. ${ }^{2}$.

La expresión "a título oneroso" que contiene el numeral 5 del artículo 20 del Código de Comercio señala que las acciones han sido negociadas con un ánimo de lucro. Si hablamos de comerciantes, en este caso debemos establecer que la “expresión 'a título oneroso', en manera alguna implica la presencia de ánimo de lucro" (Superintendencia de Industria y Comercio, 2002).

La duda, entonces, es cómo determina la Administración y, en últimas, el Consejo de Estado la delgada línea entre entidades sin ánimo de lucro no exentas del impuesto de industria y comercio por la Ley 14 de 1983 y cuándo estas pueden generar como actividad

2 Como se anotó anteriormente, la doctrina consideraba que si se encontraba dentro de una actividad económica realizada por una empresa era posible su gravamen (Parra Ortiz, 2004). 
comercial gravada la negociación de acciones establecida en el artículo 20 numeral 5 del Código de Comercio.

Por otro lado, en el caso de las personas jurídicas, para establecer que la negociación de las acciones es una actividad comercial de la empresa, esta debe estar establecida como actividad de la sociedad. La actividad deberá desarrollarse, entonces, como una obligación continua y propia de su negocio. Es posible identificar dos elementos de descripción empresariales que permiten análisis y determinaciones sobre las obligaciones de las empresas, así como de las actividades que esta tiene permitido desarrollar. Sobre aquellas actividades se determinarán los conceptos gravados de la compañía por el impuesto de industria y comercio. Dichas actividades son: el objeto social, incluyendo la capacidad de la empresa, y el giro ordinario de los negocios.

En el caso de la negociación de las acciones, el desarrollo comercial de estas debería estar establecido en el objeto social de la empresa. La capacidad de la sociedad

... se circunscribirá al desarrollo de la empresa o actividad prevista en su objeto.

Se entenderán incluidos en el objeto social los actos directamente relacionados con el mismo y los que tengan como finalidad ejercer los derechos o cumplir las obligaciones, legal o convencionalmente derivados de la existencia y actividad de la sociedad. (art.

99, CC)

En estos casos se puede considerar que los objetos sociales determinan las actividades por desarrollar de la empresa. Estas incluirán todas aquellas actividades para ser realizadas por la empresa para el cumplimiento de su objeto social.

El desarrollo de estas capacidades se verá establecido en el objeto social de la empresa. En esta se debe indicar claramente la capacidad para realizar ciertas actividades que adquirirá la compañía; el objeto social, de acuerdo con el Código de Comercio, artículo 110, determinará las actividades completas y claras que esta desarrollará. "Será ineficaz la estipulación en virtud de la cual el objeto social se extienda a actividades enunciadas en forma indeterminada o que no tengan una relación directa con aquél" (art. 110, CC). Puede, entonces, entenderse que, de no estar establecida en estas actividades la actividad de comercialización de acciones, esta no sería una actividad gravada para la empresa, pues, no se encuentra en su objeto social. Dicho objeto social es el llamado a determinar las actividades que puede desarrollar la sociedad, y por las cuales se producirán los ingresos por los que la empresa es obligada a pagar el impuesto de industria.

La duda planteada es, entonces, si puede considerarse que una empresa que no tiene determinado, dentro de su objeto social, la negociación de acciones, pero recibe ingresos por concepto de dividendos se encuentra como sujeto pasivo del impuesto de industria y comercio, obligado a ser gravado por los ingresos generados por estos activos exclusivamente.

El giro ordinario de los negocios se relaciona con las actividades que la empresa debe desarrollar, con el fin de cumplir con el objeto social de la misma. No todas las actividades, 
sin embargo, son constitutivas del giro ordinario de los negocios, es posible entender que algunas actividades se realizan para la consecución de un objeto principal. No obstante, existen actividades propias de cada una de las empresas y las entidades comerciales, que son específicas de toda actividad comercial y son establecidas por ley; estas pueden ser obligaciones de las empresas, como llevar contabilidad o los procesos bancarios de manejo de cuentas corrientes y de ahorro que no están directamente relacionadas con su objeto social, pero son necesarias para los procesos administrativos y de funcionamiento de la empresa.

Ahora bien, se entenderá que la sociedad como persona jurídica permitirá que se desarrollen las actividades incluidas en su objeto social o determinantes para el giro ordinario de los negocios. Ahora bien, queda la incógnita sobre si las actividades por ser gravadas serán aquellas establecidas en el objeto social de la empresa, limitándose a las actividades establecidas en su constitución, y de su capacidad de acuerdo con su objeto social o si se determinarán de acuerdo con el giro ordinario de los negocios.

La incertidumbre respecto a las actividades para ser desarrolladas se determina por los negocios propios de la empresa que podrían no estar tácitamente establecidos en el objeto social, y dadas las actividades, por tanto puede llegar a crearse una inseguridad con relación a las actividades empresariales, puede llegar a considerarse que los ingresos obtenidos por las empresas, por concepto de dividendos, sean gravados por el impuesto de industria y comercio en consonancia con las actividades de la empresa, consideradas o no dentro de su objeto social.

\section{- Actos de comercio}

En correspondencia con lo anteriormente señalado, el primer aspecto por analizar es la relación de las actividades comerciales determinadas en la ley, comparándolas con las actividades comerciales que se encuentran establecidas en el Código de Comercio (Ley 14 de 1983, art. 35). Es importante realizar el estudio de lo que considera el Código, en tanto comerciante, en un sentido amplio de la palabra, pues debe detallarse desde una visión subjetiva la calidad que se obtiene de quien ejecuta una actividad comercial, lo que influye en la condición material del impuesto.

En principio, según lo podemos encontrar en el Código de Comercio, y comparándolo con el sujeto pasivo del artículo 32 de la Ley 14 de 1983, "la calidad de comerciante se adquiere, aunque la actividad mercantil se ejerza por medio de apoderado, intermediario o interpuesta persona" (Código de Comercio, 2008, art. 10). En otros términos, se define a un sujeto pasivo que puede realizar la actividad de manera directa o indirecta, en el mismo entendido que por concepto de mandato o intermediario. Por tanto, en este caso es posible considerar que el comerciante, tanto para el Código como para el impuesto de industria y comercio, puede realizar sus actividades comerciales de manera personal o por intermediarios. 
En segundo lugar, el artículo 11 del Código de Comercio indica: "Las personas que ejecuten ocasionalmente operaciones mercantiles no se considerarán comerciantes, pero estarán sujetas a las normas comerciales en cuanto a dichas operaciones"; entonces, aquellos no considerados como comerciantes, como indica el impuesto de industria y comercio, desarrollan su actividad de manera ocasional y no permanente. La aclaración de si la persona debe o no considerarse como comerciante es trascendental, pues es uno de los elementos relevantes en los casos en los que se debe determinar si la persona que realiza una actividad comercial es o no un comerciante y, por tanto, realiza una actividad desde el punto de vista comercial y en conexidad con el aspecto tributario.

En tercer lugar, podemos ver que quienes son considerados comerciantes o desarrollan la actividad de comerciante de acuerdo con el Código de Comercio son "las personas que profesionalmente se ocupan en alguna de las actividades que la ley considera mercantiles" (art. 10, CC), es decir, que las personas que pasarán a ser consideradas como comerciantes deberán realizar sus actividades de manera profesional. En este sentido, se puede entrar en conflicto con lo que se consideraría como comerciante, en cuanto a la temporalidad que le asigna al sujeto pasivo el artículo 32 de la Ley 14 de 1983. En esa dirección, un comerciante no necesita realizar la actividad de manera permanente u ocasional (Ley 14 de 1983, art. 32).

Puede concluirse, entonces, que las actividades comerciales establecidas en el artículo 36 de la Ley 14 de 1983, deberán ser realizadas por personas que se consideran comerciantes para el ejercicio de actividades comerciales. De igual manera, se deberían incluir las personas naturales que desarrollen una actividad comercial determinada, de acuerdo con el Código de Comercio y la Ley 14 de 1983.

Surge el conflicto, de todas maneras, en el momento en el que se ha dado la transición de comerciante a persona natural, y el momento en el que este cambio pasa a configurar una modificación de su condición de realizador o no, de una actividad comercial. Es posible preguntarse en qué momento pasa una persona natural a realizar una actividad comercial, que le imponga la obligación de reportar sus ingresos como constitutivos del pago por el impuesto de industria y comercio.

\section{- Analogía en la norma tributaria}

Además de estas actividades, la ley se refiere a aquellas que se encuentran establecidas en el Código de Comercio. Podemos entender de este proceso de interpretación analógica de la ley tributaria, que en este caso se utiliza un proceso extensivo de la ley comercial a la tributaria. A pesar de que no se abarque el concepto en general, la ley tributaria sí se remite a la comercial con el fin de darle contenido a lo establecido en ella.

La ley comercial referida en este caso permite una analogía jurídica de complemento de la ley tributaria. Existen doctrinantes que no aceptan dicha analogía. La analogía se 
presenta cuando se llena de contenido la ley dado que existe una laguna legal ${ }^{3}$ (Cano, 2012). En este caso no es posible hablar de una laguna como de un complemento de la ley, pues, la ley misma es la que remite a la norma comercial para completar sus procesos e "integrarlos" (Álvarez, 2010, p. 85).

La ley tributaria debe considerarse completa para tener un proceso de seguridad jurídica al contribuyente; debe determinar los aspectos gravables básicos de la ley, con el fin de que el contribuyente sepa con anterioridad y con total certeza el hecho imponible de su actividad. Basada en esta seguridad no se acepta, en muchos casos, la dirección de la ley tributaria. No obstante, es posible analizar de este caso, no una analogía, pues no se permite un espacio en blanco de la ley que no se conoce, y por no tener guía se redirige a la ley tributaria. La misma ley dirige las actividades comerciales por lo que se puede considerar que es una actividad controlada y vigilada por el legislativo (Álvarez Siota, 2010).

Al final, la ley tributaria debe primar, pues estas extensiones de la norma comercial no desnaturalizan las condiciones inicialmente establecidas en la misma. Es en la ley tributaria donde se encuentran señalados los elementos básicos del impuesto de industria y comercio; además es en la Ley 14 de 1983, donde se establece de manera integrada el impuesto. La unión de la ley como una forma de dar continuidad a la ley, y así permitir que se ajuste a la naturaleza jurídica de los sujetos, le admite igualmente movimiento a la ley tributaria, para ajustarla a los hechos jurídicos que se presentan día a día.

Se revisarán como objetos materiales la visión de la ley comercial y la tributaria en sus relaciones con la ley del impuesto de industria y comercio.

\section{- Analogía al Estatuto Tributario}

Una vez revisados los procesos comerciales que se pueden observar en estos casos, se hace necesario analizar las condiciones tributarias de los dividendos y las acciones. Los dividendos obtenidos por las acciones deberán ser entendidos de acuerdo con las características de dichas acciones, en tanto activos de la empresa, para que pueda establecerse la relación de los ingresos como gravados por el impuesto de industria y comercio.

Los ingresos percibidos dependerán de la calificación de activos de las acciones. En el ámbito de la Ley 14 de 1983, no se entenderán como gravados los ingresos percibidos por la venta de activos fijos, de acuerdo con el artículo 33 de la Ley y el artículo 60 del Estatuto Tributario.

Se entiende, entonces, que las acciones que han sido negociadas por parte de la empresa serán comercializadas dentro del giro ordinario de los negocios, ya no desde un entendido de negociación de acciones como objeto social de las personas que la compran, sino desde el giro ordinario de los negocios. Como se había reseñado anteriormente, el giro

3 "Entendiendo el término de 'laguna' para describir el hueco normativo que se produce cuando no hay una disposición exactamente aplicable al caso”, de acuerdo con lo expresado por José Ignacio Cano Martínez de Velasco (2012) en su libro. 
ordinario de los negocios no se encuentra relacionado con el registro de la empresa, está dirigido de acuerdo con las actividades económicas adicionales que esta realiza.

La implicación tributaria y comercial que le asiste a la consideración de activo fijo debe ser tenida en cuenta después de que se analice en conjunto la persona natural, jurídica o de hecho que pasa a ser objeto del impuesto.

Puede concluirse, aun así, que estas son directrices que toman la norma para dar fuerza y complemento a la ley tributaria y a la regulación del impuesto; mas no por esto se determina la aplicación de la ley comercial, o en este caso tributaria, como una marca del tributo, sino que, al contrario, ayuda a dar contenido y entendimiento al contribuyente, y la Administración como activo fijo o actividad comercial cuando deba ser juzgado.

\section{Aspecto cuANtitativo}

\section{a. Base gravable}

La base gravable en el impuesto de industria y comercio se "determina sobre el promedio mensual de ingresos brutos del año inmediatamente anterior” (Piza Rodríguez, 2017, p. 169) que obtengan las personas o sociedades por el ejercicio de actividades gravadas. Aunque inicialmente se consideraban los ingresos por las actividades comerciales, industriales y de servicios, con el artículo 341 de la Ley 1819 de 2016, se realizó una modificación a la base gravable del impuesto establecido en el artículo 33 de la Ley 14 de 1983, que establece: "La base gravable del impuesto de industria y comercio está constituida por la totalidad de los ingresos ordinarios y extraordinarios percibidos en el respectivo año gravable, incluidos los ingresos obtenidos por rendimientos financieros, comisiones y en general todos los que no estén expresamente excluidos en este artículo" (énfasis agregado).

Inicialmente se había indicado que la base gravable estaba especificada de acuerdo con las actividades realizadas, pero con la ley se modifica para ampliar el concepto a todo aquello que no se encuentre claramente excluidos en ese artículo. Respecto de los dividendos, como de muchos otros hechos que pueden estar en discusión, pueden ser gravados de acuerdo con esta nueva definición del artículo.

En el caso de los dividendos se crea nuevamente la incertidumbre de si deben o no entenderse como gravados, vista la amplitud de la base gravable. En el momento en el que se determine qué es un ingreso, puede ser incluido en la base gravable del impuesto. De igual forma, deberá alinearse con los demás preceptos para considerar que no cuenta como una actividad excluida o es realizada por un sujeto no obligado; pero este dependerá de los hechos de cada caso estudiado y del proceso comercial y tributario adelantado por el contribuyente. En principio, entiende la doctrina que hay un progreso de la Administración, al considerar que los ingresos por concepto de dividendos se encuentran incluidos en la base gravable del impuesto de industria y comercio (Osorio, 2017, p. 257). 


\section{b. Tarifa}

Como se analizó, los dividendos se encuentran en el aspecto específico de las actividades comerciales. Para estas actividades se ha establecido la tarifa del artículo 33, numeral 2 de la Ley 14 de 1983. En este se expresa que la tarifa que deberá ser cobrada en estos casos, si se llega a tomar como gravado el dividendo, es del "2-10 x 1000 para actividades comerciales o de servicio". El cobro de esta tarifa se encuentra dentro de un margen de movimiento que pasa a determinar cada municipio.

\section{- Exenciones tributarias}

Finalmente, la Ley 14 de 1983, en su artículo 33 determina de manera expresa a aquellos sujetos que considera no deben ser gravados por el impuesto de industria y comercio. Estas excepciones limitarán y permitirán terminar de revisar los sujetos pasivos del impuesto de industria y comercio y las actividades gravadas.

En este trabajo nos centraremos en las actividades que se desarrollan en este ordenamiento; debido a lo anteriormente comprendido, las actividades agrícolas y de explotación y extracción tienen un desarrollo industrial claro, el cual se encuentra centrado en la actividad como tal. Por tanto, es posible separarlas de las actividades que se realizan en los diferentes establecimientos que menciona el artículo 39, y que aunque puedan ser tomadas como actividades comerciales de acuerdo con el numeral 16 del artículo 20 del Código de Comercio en el que se indica la "explotación mercantil de las fuerzas o recursos de la naturaleza", el legislador ha decidido mantenerlas como actividades no gravadas.

\section{Análisis jurisprudencial}

Continuando con el estudio del impuesto de industria y comercio se adelantará un análisis de las sentencias emitidas por el Consejo de Estado respecto del gravamen de dividendos en este impuesto. De esta manera, se abordarán las principales problemáticas del impuesto, como son el gravamen basándose en la actividad principal, el giro ordinario de los negocios, el momento en el que se enmarcan según lo establecido en el artículo 20 numeral 5 del Código de Comercio y, por último, el chequeo del gravamen de los dividendos obtenidos por las personas naturales o jurídicas cuando los mismos son obtenidos por la venta de activos fijos. Para este estudio se analizaron 98 sentencias de Consejo de Estado que tenían como tema principal el impuesto de industria y comercio en los ingresos por dividendos, de las que se terminaron tomando 46 sentencias de muestra hasta enero de 2020.

\section{A. Actividad principal y secundaria de los negocios}

Como se ha venido tratando a lo largo del artículo, las actividades comerciales, industriales o de servicio son aquellas realizadas por una empresa que genera ingresos que 
conllevan la obligación de cancelar el impuesto de industria y comercio sobre estos. Como hemos venido identificando a lo largo del trabajo, la actividad comercial es aquella que enmarca las actividades económicas establecidas como comerciales, o que se entiendan como tales en el Código de Comercio, aunque la definición en este caso es un poco redundante o simplista. Como lo analizamos en el primer apartado del escrito, las actividades comerciales o que se entiendan como actividades mercantiles o de comercio pasan a ser variadas y se subdividen según las condiciones de la normatividad respectiva.

En el caso de las actividades principales nos referimos a lo que se denomina en el Código de Comercio como objeto social, de acuerdo con lo establecido en el artículo 99 del mismo. El objeto social define las actividades que se encuentran relacionadas con la empresa y que le dan a la misma la capacidad de que desarrolle las funciones específicas para las que fue creada. El objeto social limita las actividades de la empresa y marca la ruta de esta.

Para los dividendos el objeto social, de manera inicial, se encuentra establecido en el numeral 5 del artículo 20 del Código de Comercio, el cual dice que la empresa debe constituir sociedades y administrarlas para obtener sus ingresos.

\section{Sentencias}

El primer caso que podemos analizar y que se encuentra estudiado como uno de los primeros en los que se emitió sentencia respecto al impuesto de industria y comercio es el caso The B.F. Goodrich (Sentencia 3412) que corresponde a la demanda presentada por la empresa extranjera The B.F. Goodrich, con sede en Ohio, Estados Unidos, y que participaba como inversionista en la empresa Colombiana de Llantas S.A. La empresa inicia el proceso basado en una lucha para lograr el reconocimiento jurídico de sus apoderados en la representación de la empresa ante el Tribunal de Cundinamarca, el cual se declara inhibido de dictar una decisión sin considerar el poder emitido por las entidades encargadas en Estados Unidos.

Lo importante en esta sentencia es, en principio, que para la época que la misma afronta el cobro de los impuestos de industria y comercio para los años 1981 a 1985 encontramos un cruce de normativas como "los decretos 950 de 1975 y 1901 de 1977, así como los acuerdos $21,9^{\circ}$ y $8^{\circ}$ de 1983, 1984 y 1985 respectivamente” (Sentencia 3412, The B.F. Goodrich), todos estos emitidos con anterioridad a la ley 14 de 1983 y que ayudan a cubrir los periodos que la normatividad enfrenta respecto al impuesto de industria y comercio para dividendos.

El primer objeto para tener en cuenta en la consideración de las actividades comerciales es que las mismas no se encuentran determinadas con la extensión que se plantea en los nuevos decretos o de acuerdo con las modificaciones que ha tenido la ley en este campo, sin embargo, el concepto se mantiene cercano a lo que establece la norma ${ }^{4}$.

4 Pueden considerarse los conceptos de actividades comerciales, industriales y de servicio en la sentencia, aunque en esta tampoco se extienden en los conceptos. 
En este caso, la actividad inversionista no puede entenderse como una actividad de "servicios" ni comercial, como puede ser interpretado. Aunque no se da una extensión en el concepto o el motivo por el que no se llega a considerar, se observa que se tiene en cuenta la independencia jurídica de las empresas, considerando una como extranjera y otra como nacional; así mismo, que las actividades de inversionistas no son gravadas de acuerdo con la legislación.

Citando la sentencia de The Goodrich encontramos el proceso de Banque Sudameris vs. Dirección Distrital de Impuestos (Sentencia 4209). La empresa Banque Sudameris no cuenta con sucursal o domicilio en Colombia. Sin embargo, cuenta con unas acciones en la empresa Banco Sudameris Colombia. El Distrito considera que las acciones que tiene la empresa la convierten en un sujeto pasivo del impuesto de industria y comercio, por el ejercicio de actividades comerciales de acuerdo con el numeral 5 artículo 25 del Código de Comercio (art. 20, CC) que, como hemos citado, en muchos casos manifiesta que el comerciante que desarrolla la actividad profesionalmente debe participar en la administración, negociación y negociación a título oneroso de acciones. Pero en el proceso, citando lo establecido por el consejero ponente Jaime Abella, en la sentencia The Goodrich no se puede entender que la tenencia de acciones convierte inmediatamente a la empresa en un sujeto pasivo. La empresa en ningún momento desarrolla actividades comerciales de manera profesional en Colombia y la tenencia de acciones en una sociedad no puede ser un objeto que exija que inmediatamente se entienda como sujeto pasivo del impuesto de industria y comercio, y en este mismo sentido falló el Consejo de Estado negando las pretensiones de cobro del Distrito.

Besmit Ltda. vs. Dirección de Impuestos Distritales de Bogotá (Sentencia 4548), al igual que The B.F. Goodrich, es una de las primeras sentencias de gravamen de dividendos por el impuesto de industria y comercio. La sentencia fue emitida el 3 de marzo de 1994 por el consejero ponente Delio Gómez Leyva. La empresa Besmit Ltda. tiene como objeto social el desarrollo de la actividad de inversionista. La empresa asegura que la actividad desarrollada no se encuentra contemplada como una actividad comercial, industrial o de servicios que pueda ser gravada por la dirección de impuestos, y sostiene que su empresa no cuenta con ingresos de actividades de las que tributariamente pueda considerarse el gravamen de los ingresos. Equiparando además el cobro de este tributo a la empresa que recibe los ingresos, así como la que entrega los dividendos como un problema de doble tributación en el impuesto (Sentencia 4548, Besmit vs. Dirección de Impuestos).

El Consejo procede en este caso a realizar el análisis de la mercantilidad de la sociedad. Es claro que la condición de mercantil de una empresa de estas características corresponde al ánimo de lucro y tiene el objetivo de lograr ingresos, por lo que no se discute su mercantilidad. Es además claro que la empresa tiene como objeto social y, por tanto, como giro ordinario de los negocios, la comercialización de "bienes raíces, y muebles en acciones, partes de intereses, cuotas, bonos, cédulas y demás títulos valores y papeles bursátiles”5. 
Las consideraciones del objeto social hacen evidentes las condiciones de la empresa como sujeto pasivo del impuesto considerando que desarrolla las actividades comerciales contempladas en el artículo 20 numeral 5 del Código de Comercio.

De acuerdo con la línea de las sentencias de The Goodrich y del Banque Sudameris, se maneja la Sentencia de Lloyds Bank (Blsa) Limited (antes Banco de Londres y América del Sur). Loyds Bank posee acciones del Banco Anglo Colombiano. Al igual que en las anteriores sentencias se define si la empresa extranjera no tiene otro proceso económico diferente a las acciones que posee de la empresa colombiana. La consideración de la sala se resume en el precedente de las sentencias anteriores en las que se dice que la posesión simple de acciones en una empresa colombiana no representa la realización de una actividad económica en las empresas. Por tanto, las empresas no son tomadas como sujetos pasivos del impuesto de industria y comercio.

Siguiendo con estas sentencias podemos ver el caso de Casa Toro S.A. vs. Dirección de Impuestos de Bogotá; la Sentencia 9086 se centra en el procedimiento de notificación y los errores tipográficos y de indebido derecho de defensa de la empresa ante los requerimientos de la Dirección. En este caso nos centramos en el objeto social de la empresa frente a los ingresos por concepto de dividendos; al respecto se observa que los mismos no se encuentran contemplados en su objeto social ni hacen parte del giro ordinario de los negocios de la empresa, por lo que es posible, entonces, desligar a la empresa de la obligación de declarar y pagar el impuesto de industria y comercio al no encontrar una relación en su objeto social o con las actividades que realiza, pues no lo hace de manera habitual o que tenga una clara influencia en el desarrollo de sus actividades diarias.

Es importante en este caso mostrar los salvamentos de voto de la sentencia. En este caso, el consejero Delio Gómez Leyva mantiene la misma posición que tenía en Besmit Ltda. y considera que la mercantilidad de la empresa es primordial para la consideración de su obligación de declarar y pagar el impuesto de industria y comercio. Establece que el hecho de realizar actividades económicas como empresa mercantil crea ingresos por dividendos que deben ser comerciales por conexidad. Además de negar el precedente de la sentencia de The B.F. Goodrich, para empresas extranjeras con servicios en Colombia, no para empresas colombianas, lo que limita el margen de aplicación de las decisiones del precedente respecto al objeto social de la empresa como determinante para establecer el sujeto pasivo.

El consejero Daniel Manrique Guzmán, por su lado, maneja una teoría aún más extensa respecto al objeto social y el gravamen de los ingresos por dividendo, considerando que en el caso de que se tengan ingresos por dividendos y actividades de dividendos en una empresa es posible gravarlos con el impuesto de industria y comercio. Las actividades de las empresas en muchos casos son comerciales y, por tanto, las actividades de dividendo deben ser comerciales por extensión.

El caso Fanalca vs. el municipio de Yumbo (Sentencia 10066), del año 2000, cuenta con la particularidad de enfocar dentro de la misma sentencia muchos temas, como son el arrendamiento de equipos de transporte, la diferencia de cambio y la participación de la 
empresa en consorcios en distintas ciudades de Colombia. Para los dividendos, el consejero ponente Daniel Manrique Guzmán mantiene la posición de que el gravamen de los dividendos y los ingresos obtenidos por la empresa debe ser de carácter extensivo y abarcando cualquier actividad desarrollada por la empresa. El municipio de Yumbo, siguiendo la Ley 14 de 1983, grava todas las actividades comerciales, sin entrar a hacer diferencias entre una y otra actividad, por tanto, es posible gravar los ingresos obtenidos por dividendos en cada uno de los casos. Además, como indica la sentencia, el objeto social de la empresa incluye, de acuerdo con el certificado de cámara de comercio entregado al Consejo: “11) la inversión y administración de capital en acciones, títulos y bonos y cualquier otro valor bursátil" (Sentencia 10066). Por lo que se concluye que la mercantilidad de la empresa y su relación con lo establecido en el artículo 20 numeral 5 del Código de Comercio permite que se graven los ingresos por concepto de dividendos.

La empresa Delima y Cía Medellín Ltda. (Sentencia 13058) se enfrenta al municipio de Medellín. La discusión pasa a enfocarse en las acciones como activos fijos y, por tanto, será tratada de manera más amplia en este aparte. Sin embargo, en este caso es importante mencionar el estudio que se hace del certificado de representación de la empresa. El Consejo de Estado estudia el objeto social de la empresa, el cual se centra en su función como compañía aseguradora, y no es posible tomar de este la idea de que realiza como objeto social o giro ordinario los negocios la venta de acciones. El municipio, por su lado, indica que el no tener prohibida la actividad puede ser tomado como una posibilidad de realización de la acción.

El caso de Colseguros vs. Secretaría de hacienda de Bogotá (Sentencia 13726) nos indica que en este momento jurisprudencial el gravamen de los ingresos por dividendos corresponde claramente al objeto social de la empresa. En este caso, sin embargo, se ve una particularidad y es la enajenación de acciones dentro de un mismo grupo empresarial, el cual ha pasado a absorber y a manejar, de acuerdo con una reorganización administrativa, las acciones de la empresa. Establece el Consejo de Estado que la venta de acciones que genere ingresos en estos casos específicos no puede llegar a considerar la utilidad como sujeta al gravamen por el impuesto de industria y comercio considerando que este ingreso se genera como cumplimiento de una política administrativa que asume el grupo empresarial y nada tiene que ver con los conceptos de objeto social de la empresa de acuerdo con su certificado en Cámara y Comercio.

Como se señaló al principio del apartado, una de las sentencias hito que trata este tema, y que se analiza de manera amplia en este aparte, es la Sentencia 14876 de 2005, de la Fábrica Nacional de Chocolates, por la relevancia que adquiere en este caso la discusión no solo de la actividad que realiza la empresa en el desarrollo de su objeto social, sino también del objeto social y la forma como esta empresa permite la realización de actividades conexas para su desarrollo económico. En esta sentencia se ve la diferencia entre el hilo que se había venido marcando con las primeras empresas extranjeras que tenían inversiones en Colombia y se centra en las empresas colombianas, su objeto social y las actividades mercantiles que le ordenan el pago del impuesto de industria y comercio. Un 
hecho relevante de este es, además, la inclusión y unificación de la legislación nacional y municipal del impuesto, donde cobra relevancia la separación de poderes y la autonomía de los municipios en el gravamen de los impuestos, así como la amalgama que se debe realizar con las leyes nacionales y su cumplimiento y analogía.

Continuando con las sentencias, vemos el caso de Inversora S.A. (Sentencia 16054), una de las empresas del grupo Bolívar que crean una línea de decisiones por parte del Consejo de Estado respecto de la venta de acciones realizadas por esta. La sentencia es decidida en función de la caracterización de la compañía como con activos fijos, no obstante, en este mismo sentido la empresa entra a identificarse como un grupo empresarial. El problema de la determinación del grupo empresarial gira alrededor de los diferentes objetos sociales que tiene la empresa dentro de sus procesos propios; muchas de las que se encuentran atadas a esta guían la diferencia en el objeto social de cada una. En esta sentencia se analiza la venta de acciones de tres empresas del grupo y, por tanto, entra a determinar que ninguno de los objetos sociales incluye la venta de las acciones, sino, por el contrario, buscan mantenerlas dentro de su patrimonio como inversión.

La empresa Inversiones Brembo S.A. marca una línea de sentencias que se desarrollarán a partir de esta. La sentencia se refiere a una empresa cuyo objeto social es invertir en acciones, mantenerlas en su patrimonio y no enajenarlas sino obtener ingresos de estas. La empresa, en su momento, decidió vender acciones que tenía dentro de su patrimonio. El Distrito realiza una inspección tributaria de la que surgen los problemas de tiempo para la presentación de los recursos y la resolución. En este caso la empresa indica que la inspección no detiene los tiempos para dar respuesta y dejar en firme la resolución, por tanto, no es posible que el Distrito imponga sanción. Por el otro lado, el Distrito se defiende indicando que el requerimiento especial se encontró suspendido por tres meses y cuenta con el tiempo para emitir los actos administrativos que modifican la declaración privada (Sentencia 16206). En el caso de los dividendos se refiere a la venta de acciones en las que la empresa las conserva en su patrimonio, por tanto, no pueden ser gravadas. No obstante, la actividad mercantil de la empresa y su objeto social guían a la decisión de que se encuentran siempre en la actividad comercial de inversión y venta de acciones de manera ordinaria. El Consejo de Estado, sin embargo, da un giro al argumento de la Administración basándose en el certificado de existencia y representación el cual indica que los bienes son obtenidos con el fin de que se mantengan en su patrimonio, por tanto, sustenta que son activos fijos, pues en ningún momento el objeto social decide que se van a vender, sino que, al contrario, indica que la empresa los conservará y no los venderá en ese momento o durante el giro ordinario de los negocios como alega la Administración. El Consejo de Estado termina confirmando el fallo del tribunal en el que se anulan los actos administrativos por el objeto social de la empresa, no por la extemporaneidad de la respuesta.

En esta misma línea del giro ordinario de los negocios encontramos a la empresa Inversora 2020 S.A., la cual tiene dos sentencias dictadas en el mismo año, con 4 meses de diferencia; la primera estudiada por la consejera ponente Martha Teresa Briceño de Valencia, de fecha 2 de abril de 2009 (Sentencia 16790, Inversora 2020 S.A. vs. DIAN), y la 
segunda dictada por el consejero ponente: Héctor J. Romero Díaz, el día 13 de agosto de 2009 (Sentencia 16788, Inversora 2020 S.A. vs. DIAN). Debido a la similitud de los casos, los actores y el fallo trataremos las dos sentencias en este mismo punto. Como su nombre lo indica, esta es una empresa de inversión en acciones que tiene dentro de su objeto social la inversión y venta de estas bajo cualquier modalidad. En muchos casos, estas acciones son entendidas como activos fijos, pues, a la empresa no le interesa la venta de las acciones, sino su conservación para la obtención de ingresos por la renta pasiva.

En los dos casos se adjuntan los certificados de existencia y representación de la empresa con los que la Administración intenta demostrar que la empresa tiene dentro de su objeto social la negociación de acciones sin ningún tipo de distinción o hecho adicional, lo que la condena. Sin embargo, en un giro de la Administración, el Consejo de Estado fundamenta su decisión en este mismo certificado de la empresa con una diferencia. El certificado dice claramente que la adquisición de las acciones se realiza con el objetivo de tenerlas en el patrimonio de manera permanente. Por tanto, contrario a lo que indica la Administración, el objeto social refuerza la decisión de la empresa de tener las acciones de forma permanente en su haber y no, como lo indica la Administración, con un fin comercial. En estos dos casos se refuerza la idea de que en el gravamen o no de las acciones y los ingresos por dividendos se debe tener en cuenta, no solo el objeto social de la empresa, sino también la intención con la que la misma ha sido obtenida, lo cual afecta la decisión de si el objeto social incluye o no la venta de acciones en el giro ordinario de sus negocios, o solo la obtención de ingresos y dividendos por las mismas. Una decisión muy en línea con la decisión adoptada por la empresa en los casos de Inversiones Brembo S.A.

El caso Sociedad Bolívar en contra de la DIAN (Sentencia 16789), no le da prioridad al objeto social de la empresa -como se ha visto, el objeto social incluye la obtención de acciones que la empresa decide conservar como activos fijos-. Considerando esto, el Consejo no se centra en el objeto social sino en la intención de la empresa con los bienes, pues ve que el objeto social incluye la inversión, sin embargo, al optar por esta como activo fijo, su acción no se tiene dentro del giro ordinario de los negocios.

La Sentencia 17953 de Inversiones Colmena S.A. es diferente en el hecho de incluir dentro de la discusión los contratos de participación de la empresa. Esta sentencia se refiere a la solidaridad que la Administración argumenta tienen los contratos de colaboración debido a que en uno de los contratos realizados la empresa Colmena, como socio oculto, no pagó el impuesto de industria y comercio el cual fue asumido en su totalidad por el socio gestor. Además, se discute que las acciones que han sido vendidas por la empresa hacen parte del giro ordinario de los negocios de esta y son mercantiles debido a que la compañía ejerce actividades comerciales.

El Consejo de Estado, en este caso, analiza el objeto social de la empresa y continúa con la línea del precedente que analiza en casos anteriores y es que el certificado de existencia y representación indica la voluntad de permanencia con la que las acciones son adquiridas y, por tanto, no se puede entender que la venta se dé dentro del giro ordinario de los negocios de la empresa. En cuanto al impuesto generado por el contrato de 
participación, se refiere a la verdad real sobre la verdad formal y es que si la Administración ha recibido de uno de los socios un pago completo no puede exigir que el otro socio realice un pago de su porcentaje pues se consideraría un doble pago. Aunque el contrato en principio debe ser pagado de acuerdo con la intervención no puede negarse la existencia de un pago y exigir una solidaridad en el pago del impuesto.

Posteriormente, en 2010, se presenta el caso de la empresa Valmiera Enterprise Corp. y Cia. S. en C. vs. Secretaría de Hacienda (Sentencia 17339), quien disputa el gravamen del impuesto de industria y comercio por los ingresos obtenidos. En este caso, la disputa se centra en acciones que contaban con 3 y 4 años respectivamente en la empresa y que fueron vendidas. La empresa adjunta y presenta como prueba de la intención de tener las acciones como activos fijos el certificado del revisor fiscal y la contabilidad que se realiza a las acciones. La Secretaría de Hacienda, por su lado, señala que el objeto social de la empresa permite la venta de las acciones por lo que estas pueden ser realizadas de acuerdo con el giro ordinario de los negocios de la empresa.

El Consejo de Estado mantiene en este caso su precedente, como se pronunció en su momento respecto a Inversora 2020 S.A. en sus dos sentencias de 2009. En este caso, el Consejo de Estado vuelve a fallar tomando como base el objeto social de la empresa. Así, el objeto social que permita la venta de acciones no da pie a entender que indiscutiblemente este es el giro ordinario del negocio de la empresa. Todo lo contrario, el análisis del certificado de existencia y representación de la empresa permite ver la posibilidad de la venta de acciones, pero, igualmente, establece que el objeto de la compañía es el de mantener dentro de su patrimonio las acciones con el fin de adquirir dividendos de estas. Por esto, se accede a las pretensiones de la empresa revocando el gravamen de los ingresos obtenidos por esta.

En el caso Promotores de Inversiones Arroba S.A. vs. Distrito Capital (Sentencia 18122) entramos a contemplar una empresa que tiene dentro de su objeto social la actividad inversionista. La actividad desarrollada dentro del giro ordinario de los negocios se basa en la colocación de acciones para la obtención de ganancias futuras. En todo momento, el desarrollo de la empresa gira en torno a la obtención de ingreso por las acciones. La compañía, por su parte, alega que esto se refiere a la obtención de acciones con el fin de tenerlas como activos fijos. Es evidente para el Consejo de Estado que no existe la posibilidad de tener las acciones como activos fijos considerando la discrepancia entre la intención continua de la empresa como actividad comercial primaria y secundaria de la colocación de acciones para la obtención de ingresos. Los activos fijos normalmente no se encuentran en el proceso de contabilización y se alejan de las actividades principales de la entidad, hecho que en este caso no se presenta. La evidencia de la interiorización de los activos obtenidos por la empresa como parte de su objeto social se ve incluso en el hecho de que no se acepta una posible discrepancia de conceptos para solicitar que no se imponga la sanción por inexactitud.

El consejero ponente, William Giraldo Giraldo, ha decidido en la Sentencia 18702 del 27 de septiembre de 2012, en el caso entre Redifin S.A. en Liquidación vs. Secretaría de 
Hacienda de Bogotá. Se disputa que la empresa enajena las acciones fuera del giro ordinario de los negocios puesto que su intención es mantener las acciones como activos fijos y no realizar su venta. La Secretaría de Hacienda de Bogotá, por su parte, afirma que las acciones vendidas deben estar incluidas en la base gravable del impuesto al haber sido vendidas en el giro ordinario de los negocios. El Ministerio Público, por su parte, apoya a la demandante afirmando que la intención de esta es mantener las acciones dentro de su patrimonio.

El Consejo de Estado afirma que las acciones se encuentran excluidas del gravamen del impuesto de industria y comercio debido a que la compra y venta de las acciones no se está dentro del giro ordinario de los negocios, tanto el objeto social de la empresa como su contabilidad e intención siempre giran ante la posibilidad de mantener las acciones dentro del patrimonio de la compañía.

En otro caso, la Promotora de Inversiones Arroba vuelve a entrar en disputa con el Distrito Capital de Bogotá, la Secretaría de Hacienda Distrital y la Dirección Distrital de Impuestos. En este caso, la demandante indica que los activos fijos no se encuentran gravados; señala que los activos fijos o móviles no son el objeto social, el tiempo de posesión ni el registro contable de los activos. Lo que determina que sean activos fijos es que los bienes no se enajenen dentro del giro ordinario de los negocios y tener un ánimo de permanencia de las acciones. La Administración indica que la demandante tiene como objeto social la venta de acciones y no puede diferenciarla del objeto secundario.

El Consejo de Estado indica de manera muy clara que la realidad que debe primar en estos casos es que las acciones no se vendan dentro del giro ordinario de los negocios. El factor objetivos de la empresa siempre debe primar sobre el factor formal de la misma. Este hecho es puesto de presente en la sentencia cuando se observa en este proceso el numeral 5 del artículo 20 del Código de Comercio en el que se dice:

Acudiendo a la definición legal del Código de Comercio, se encuentra que la venta de acciones es un acto mercantil "para todos los efectos legales". Señala el numeral 5o del artículo 20:

"Son mercantiles para todos los efectos legales: [...]

5) La intervención como asociado en la constitución de sociedades comerciales, los actos de administración de las mismas o la negociación a título oneroso de las partes de interés, cuotas o acciones".

La expresión "para todos los efectos legales" resalta el hecho de que para considerar estos actos como mercantiles, prevalece el factor objetivo (condición del acto) sobre el subjetivo (que sean realizados por un comerciante). Sin embargo, el hecho de que la venta de acciones, incluida en la enumeración legal citada, sea siempre mercantil sin interesar quien la realice, no determina necesariamente que siempre esté gravada con el impuesto de industria y comercio, como se dilucidará a continuación. 
Lo citado anteriormente permite concluir que estas acciones fueron vendidas por rentabilidad, conveniencia o necesidad, no dentro del giro ordinario de los negocios.

Continuando con el estudio de las sentencias nos referimos a la 18903 de la Organización Corona S.A. vs. Secretaría de Hacienda Distrital y Dirección Distrital de Impuestos, donde se disputa que las acciones que fueron vendidas por la empresa no se encuentran gravadas, pues, corresponden a la venta de activos fijos. La empresa no realiza actividad de inversión con fines especulativos, sino que los tiene durante un tiempo indeterminado, ejemplo de esto es que las acciones estuvieron dentro del patrimonio de la empresa por un periodo de siete años.

El Consejo de Estado apoya lo planteado por la demandante y confirma la sentencia del Tribunal en la que se declara la nulidad de las acciones debido a que estas no estuvieron dentro del giro ordinario de los negocios de la empresa, por lo tanto, no se deben gravar.

En la Sentencia 18703, Inversiones Gutierres y Cía. S.C.S. vs. Dirección Distrital de Impuestos, se discute que los ingresos obtenidos por la venta de acciones son considerados activos fijos por parte de la empresa. La compañía cuenta con el tiempo de permanencia, objeto social y contabilización de las acciones como activos de la empresa. La Administración alega que del objeto social de la empresa se puede deducir que la venta de acciones se da por acciones gravadas.

Es evidente que la ley excluye la venta de activos fijos de la base gravable del impuesto de industria y comercio, pero se tiene en cuenta que la sociedad contabilizo la inversión, así, es claro que la persona jurídica tuvo el propósito de que los bienes permanecieran en su patrimonio. Basado en esto se confirma la sentencia del tribunal en la que se declara la nulidad de los actos demandados.

En otro caso, Proyectar Valores S.A., en una disputa con el Distrito Capital de Bogotá, resalta la labor de la empresa como inversionista, tanto de inversiones realizadas por terceros como de realizadas con recursos propios. Las actividades comerciales de la empresa se dan cuando esta desarrolla a nombre propio actividades de inversión de capital. La empresa dice que la actividad está dada como comisionista de bolsa y de inversión desarrollando solamente una actividad de servicio y no una comercial como quiere llegar a presentarla la empresa (Sentencia 19346).

El Consejo de Estado, en esta sentencia, explica un punto muy importante que no es tratado en otros documentos, pero que aclara una duda que se presenta en la base gravable del impuesto de industria y comercio y es que en su gravamen se incluyen todos los ingresos, pero nunca se define qué es un ingreso. La Sentencia 19346, sin embargo, define que: ni la norma territorial ni la que regula el tributo a nivel nacional definen el concepto "ingresos". No obstante, como uno de los objetivos de la información contable es fundamentar la determinación de las cargas tributarias, se acudirá a la definición contenida en el artículo 38 del Decreto 2649 de 199330, cuyo texto dice:

Los ingresos representan flujos de entrada de recursos, en forma de incrementos del activo o disminuciones del pasivo o una combinación de ambos, que generan 
incrementos en el patrimonio, devengados por la venta de bienes, por la prestación de servicios o por la ejecución de otras actividades, realizadas durante un período, que no provienen de los aportes de capital. [...]

En consecuencia, tratándose del impuesto de industria y comercio para su cuantificación debe tenerse en cuenta el total de los ingresos, entendidos como los beneficios o utilidades obtenidos por el contribuyente, de la realización de las actividades gravadas, durante el bimestre correspondiente, datos que pueden tomarse de la contabilidad y de los respectivos soportes contables. (Sentencia 19346, Proyectar Valores S.A. vs Distrito Capital de Bogotá)

Bajo este entendido, la sentencia pasa a diferenciar los ingresos que deben o no ser gravados y decide que mientras que en la inversión de acciones y el desarrollo de la actividad de inversionista de bolsa de la empresa se desarrolla una actividad de servicio a nombre de un tercero, en la inversión de acciones y dinero a nombre propio se está realizando una actividad netamente comercial cuyos ingresos deben ser gravados con el impuesto de industria y comercio.

Las sentencias 20768, 21036 y 21918, que resuelven el conficto legal entre el municipio de Bucaramanga vs. Electrificadora de Santander, analizan una situación similar a la dada entre la empresa Inversora 2020 S.A y la administración tributaria. En efecto, en los tres fallos los hechos son casi análogos, se diferencian en los periodos gravables de las sentencias. La primera sentencia es la 20768, Electrificadora de Santander S.A. vs. Municipio de Santander S.A. E.S.P., del 11 de mayo de 2017 de los periodos gravables del año 2005. La segunda es la sentencia 21036, Electrificadora de Santander S.A. vs. Municipio de Santander S.A. E.S.P., del 18 de mayo de 2017; y la tercera sentencia es la 21918, Electrificadora de Santander S.A. vs. Municipio de Santander S.A. E.S.P., del 29 de junio de 2017. Estas sentencias fundamentan su caso en que la empresa Electrificadora de Santander presta servicios a la población; en este proceso ha decidido modernizar unos equipos por lo que ha decidido vender activos fijos, estas ventas no se realizan normalmente dentro del giro ordinario de los negocios. Igualmente, la empresa realizó un registro de una diferencia de valores y rendimientos financieros que crea una diferencia de valores entre lo contable y lo fiscal. Los argumentos de la Administración no son extensos y se centran en que la diferencia contable y fiscal no se encuentra correctamente justificada.

El Consejo de Estado define en todas las sentencias que no existe una correcta sustentación y prueba de que los ingresos han sido contabilizados o pagados en otros periodos, por lo que apoya el argumento de la Administración de que la empresa no tiene material probatorio o justificación que fundamente la decisión de omitir el gravamen de los ingresos.

La empresa Mislo III Ltda., en liquidación, y Mislo II \& Cía S.A.S. se enfrentan al Distrito Capital, la Secretaría de Hacienda y la Dirección Distrital de Impuestos de Bogotá en una disputa por el impuesto de industria y comercio no pagado por la empresa, hecho que las mismas niegan. Las empresas fueron beneficiarias en la escisión de la compañía 
Nuevas Inversiones S.A.S., la cual procedió a darles acciones a cada una de las empresas en un proceso de fusión y escisión que conlleva la transferencia de bienes en bloque, incluyendo dentro de estos los activos, pasivos y patrimonio de la misma (Sentencia 20602).

La Administración asegura que toda transmisión de acciones y dado el recibimiento de aquellas que obtienen las empresas debe considerarse como un ingreso puesto que aumenta el patrimonio de estas. Además, al realizar las dos empresas actividades comerciales da el tono de comercialidad de las acciones para considerarlas como ingresos operacionales.

El Consejo de Estado resuelve diciendo que la venta que se realiza de las acciones por procesos de fusión y escisión no es comercial. El proceso de escisión y fusión de las empresas comerciales no es en ningún momento una compraventa, novación o subrogación teniendo en cuenta que este proceso conlleva las transferencia de estas sin generar un impuesto a cargo, anulando los actos acusados.

El caso El Zuque S.A. vs. Secretaría de Hacienda Distrital (Sentencia 21776), es una de las sentencias más completas y que mejor recopila la información que a lo largo del trabajo se ha ido expresando respecto de los momentos en los que los ingresos obtenidos por concepto de dividendos deben ser gravados. El Consejo analiza los casos en los que se debe entender como actividad principal, es decir que el objetivo de la empresa es claramente el dedicarse a la comercialización de activos por concepto de dividendos y busca desarrollarse en la actividad de inversión de acuerdo con lo que establece el artículo 20 numeral 5 del Código de Comercio. Muchas de estas empresas se encuentran con esto como objeto social, pero cuando no es así, se habla del giro ordinario de los negocios, es decir, las actividades que normalmente realiza la empresa para desarrollarse y obtener ingresos. El giro ordinario de los negocios permite que la definición de la empresa no se limite al objeto social, pues en estos casos muchas empresas consideran los activos bajo un lente distinto al que maneja la Secretaría. El giro ordinario de los negocios marca la mercantilidad básica de la empresa y debe verse de acuerdo con su día a día.

La sentencia de El Zuque marca una línea de sentencias en la que el objeto social de la empresa no es lo único que permite definir que un ingreso por dividendo y activo fijo puede o no ser gravado por el impuesto de industria y comercio. La decisión lleva a crear una línea de test de los activos fijos en los que la empresa no solamente toma en cuenta la contabilización, sino también el objeto social, el giro ordinario de los negocios y la intención que tiene. Estas cuestiones son tomadas como un todo, no se analiza un caso a la vez, sino que todos son estudiados en conjunto y por medio de esto se decide si debe o no ser gravada. Este método de test es un poco más complicado, pero más completo para tomar este tipo de decisiones.

La Sentencia 23009 de Socineg S.A. vs. Secretaría de Hacienda Distrital, indaga por el objeto social de la empresa en la que se incluyen las actividades de inversión, como actividad principal, encerrando además todas las que dentro del giro ordinario de los negocios se realizan. En este caso, la actividad de la empresa es la de inversión. Cabe aclarar que la sentencia en este caso establece que el gravamen de los dividendos no está limitado a lo que se contempla en el objeto social; si dentro del giro ordinario de los negocios y las 
actividades normales realizadas por la empresa para mantener su comercio se encuentran el manejo, la compra y la venta de acciones con el fin de obtener ingresos, se entra a considerar el gravamen de las acciones por parte de la empresa, aun cuando no se observa que el objeto social de la empresa incluya la actividad inversionista. Pero, en este mismo sentido, no se puedo ubicar dentro de lo establecido por la empresa otra actividad comercial que permitiera diferenciarlo y crear otra intención que la de la colocación de acciones como actividad comercial gravada, motivo por el cual se grava.

Aminversiones S.A., vs. Distrito Capital (Sentencia 22374 del 4 de octubre de 2018), es un caso en el que se disputa la inclusión de los ingresos por concepto de dividendos. Esta es la primera sentencia, después de la de El Zuque, en la que se analizan los criterios para que se incluyan o no los ingresos. La disputa se centra en que, según la demandante, los ingresos son obtenidos por acciones que se encuentran en el patrimonio de la parte y que la misma no tiene dentro del giro ordinario de los negocios. La Administración, por su parte, alega que dichos ingresos se dan dentro del giro ordinario de los negocios.

El fallo en este caso determina que la actividad de percepción de dividendos es respecto al numeral 5 del artículo 20 del Código de Comercio. Así mismo, la actividad comercial de la empresa es la realización de inversiones de acuerdo con el mencionado Código, y en ningún momento su carácter comercial ha sido negado por la empresa, es posible entonces gravar los dividendos de la empresa y gravar parcialmente la Resolución.

El 18 de octubre de 2018 se dicta la Sentencia 22452 en el caso de la empresa Amalfi Botero y Cía. S.A. en contra del Distrito Capital. Esta sentencia enmarca perfectamente la idea del gravamen de los ingresos por dividendos que recibe la empresa. Aunque la discusión se centra en una solicitud de corrección de la declaración de industria y comercio es interesante la referencia del fallo al objeto social de la empresa. En esta sentencia, la empresa indica que solicitó la devolución del pago de lo no debido por concepto de industria y comercio, y no por la solicitud de los saldos a favor presentados en la declaración. Por esta diferencia de solicitudes afirma la demandante que no era requerido que realizara la corrección de las declaraciones.

La razón por la que la empresa dice que no debe pagarlos es debido a que los ingresos corresponden a dividendos, los cuales no están gravados, basando esta solicitud en unas sentencias y un precedente citados por la demandante que soportan la solicitud realizada. La Administración, por su parte, alega que el proceso realizado por la empresa es equivocado pues en ningún momento hizo la corrección de la declaración y basó todo su argumento en un precedente erróneo; sin embargo, que dado el objeto social de la empresa y su desarrollo comercial, esta debe tener ingresos gravados.

La Sentencia 23700, referente al caso Actiunidos S.A. vs. Distrito Capital, continúa el precedente que han marcado las sentencias anteriores desde El Zuque S.A. La empresa argumenta que realiza sus actividades como rentas pasivas y con base en esto se entiende que las acciones no son gravadas, sobre todo porque los bienes provienen de los activos fijos de la empresa. Se argumenta que los ingresos que se tienen en cuenta se refieren a un mayor valor de las acciones, lo cual no quiere decir que las empresas se encuentren dentro 
de las actividades de compraventa. La Administración argumenta que se tiene en cuenta que se constituyan actividades comerciales de la empresa. La mercantilidad de las acciones se da para tener en cuenta el objeto social y su mercantilidad por conexidad.

El Consejo de Estado repite los conceptos que se aplican en el proceso de la sentencia de El Zuque y las demás que marcan el precedente. Por tanto, se busca la negociación del objeto social principal o secundario, y las acciones o participación de las que se derive el ingreso hacen parte del activo fijo o movible de la sociedad. Toma en cuenta la contabilización de los bienes, la intención y el objeto social que maneje la sentencia. En este caso, según el certificado de existencia y representación de la empresa se advierte su actividad inversionista y, por tanto, procede la adición de ingresos gravados.

La sentencia que analizaremos por último es la 23907 del 1 de marzo de 2019, de la consejera Stella Jeannette Carvajal Basto. La sentencia del caso Inversiones Valí Ltda. \& Cía S.C.A vs. Municipio de Medellín se basa en una solicitud de pago de lo no debido o pago en exceso realizado por la empresa que dice que canceló por los ingresos que tiene en otras empresas, pero que no realiza la inversión de acciones dentro del giro ordinario del negocio, ni debe pagar por el arrendamiento de bienes inmuebles propios.

El municipio de Medellín alega que la inversión en acciones y bienes inmuebles hace parte del objeto social de la empresa por lo que puede ser gravada por esto. Además, la empresa no aporta pruebas de que los inmuebles sean propios o de que las acciones no correspondan a ingresos que estén fuera del giro ordinario de los negocios.

El Consejo de Estado apoya el argumento del demandado en el que se dice que no se tienen pruebas de que los inmuebles y los ingresos no se encuentren dentro del giro ordinario de las acciones o sean propios. Y que una actividad habitual es muy distinta a la periodicidad con la que se puede realizar una acción. Sin embargo, la sentencia cuenta con una consideración que permite observar el motivo por el que se gravan estos dividendos al indicar que:

... para efectos de ICA es determinante establecer si los actos mercantiles realizados por una persona jurídica se enmarcan en el giro ordinario de sus negocios.

En ese contexto, reiteró que cuando la ejecución del acto de comercio previsto en el numeral 5 del artículo 20 del C. de Co., esto es, "[1]a intervención como asociado en la constitución de sociedades comerciales, [...] o la negociación a título oneroso de las partes de interés, cuotas o acciones" es ocasional, dicho acto de comercio no constituye actividad mercantil gravada con este tributo, pero, cuando esta actividad se ejerce de manera "habitual y profesional, sí, caso en el cual, la base gravable del impuesto la constituye el ingreso que se percibe por concepto de dividendos pues es la forma en que se materializa la ganancia obtenida por la ejecución de la referida actividad mercantil". ${ }^{6}$ (Énfasis agregado) 
El Consejo de Estado decide que no se cumplen los presupuestos sustantivos de la exclusión de ingresos, no hay pruebas de la procedencia de los ingresos en disputa y, por tanto, confirma que se nieguen las pretensiones de la demanda.

Al final, la decisión del Consejo de Estado se une a la del tribunal. Los ingresos que la empresa está recibiendo deben ser gravados por el impuesto de industria y comercio debido a que la empresa establece en su objeto social uno de los casos por los que se considera deben ser gravados los ingresos. Amalfi Botero S.A. desarrolla de manera comercial la intervención como asociada en la constitución de las sociedades. Este objeto social es explícitamente lo establecido en el numeral 5 artículo 20 del Código de Comercio; este artículo, como se ha manifestado en el documento, se refiere a los casos en los que la ley define que se deben gravar los ingresos obtenidos por dividendos. Esta es la decisión final del Consejo, quien falla en contra de las pretensiones de la demandante.

¿Determina el objeto social de la empresa la obligación de pagar el impuesto de industria y comercio por concepto de ingresos por dividendos?

\section{Figura 1. Gravamen dividendos en ica 1}

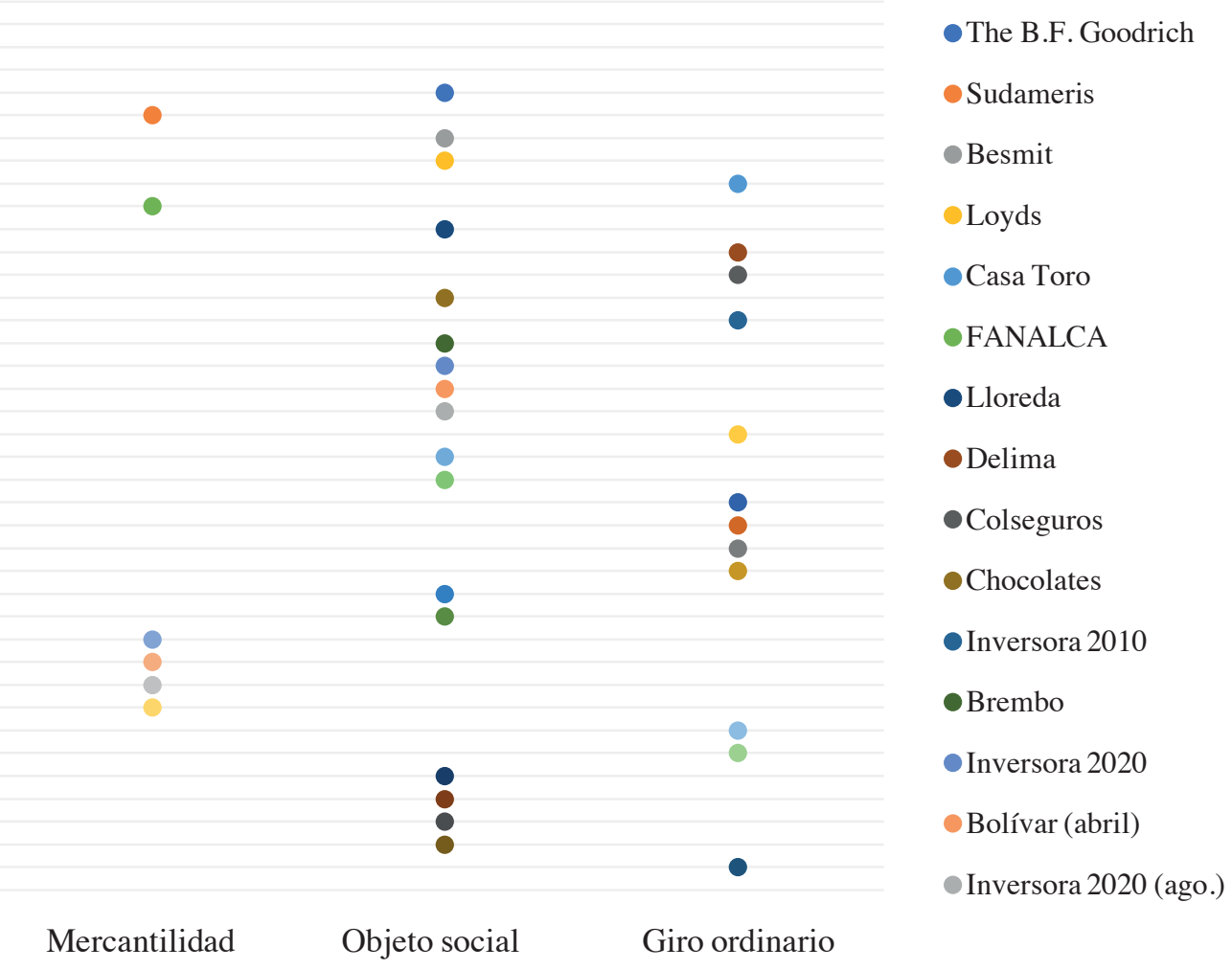

Fuente: Ministerio de Hacienda. 
Figura 2. Gravamen dividendos en iCa 2

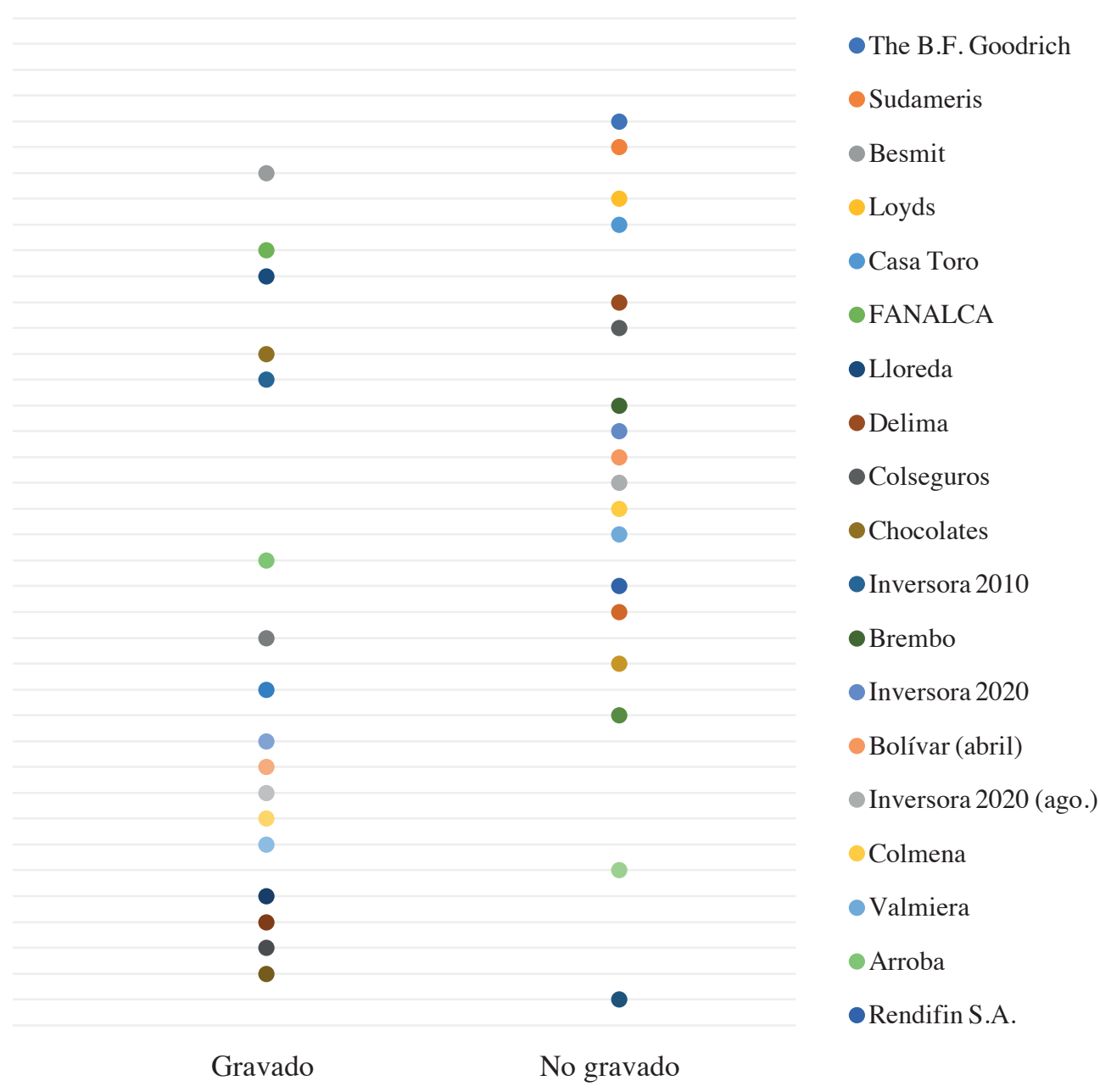

Fuente: Ministerio de Hacienda.

\section{B. Activos fijos}

El gravamen de dividendos por activos fijos se encuentra contemplado en el artículo 66 del Estatuto Tributario en el que se cita: "Artículo 33. [...] No hacen parte de la base gravable los ingresos correspondientes a actividades exentas, excluidas o no sujetas, así como las devoluciones, rebajas y descuentos, exportaciones y la venta de activos fijos" (Ley 14 de 1983).

De las 46 demandas que se estudiaron, 19 sentencias toman como su soporte y sustento principal los activos fijos como hechos de exclusión del gravamen del impuesto de 
industria y comercio, es decir, un $41 \%$ de las sentencias solicitaron que las acciones no se graven por corresponder a ingresos por activos fijos.

En el caso de la Sentencia 4548, de Besmit Ltda., no se hace una gran referencia a los ingresos por ventas de activos fijos, pues la actividad principal de la empresa corresponde a la de la inversión en estos activos, entre otras. Así, los activos fijos se mantienen, en todo caso, como ingresos excluidos del gravamen de industria y comercio según la legislación tributaria.

La Sentencia 9086, de la empresa Casa Toro S.A. vs. Dirección de Impuestos de Bogotá, señala que se realizaron inversiones en activos fijos. En el momento en el que se realiza el análisis de la obligación de declarar de la empresa se dejan al lado los conflictos procedimentales que se tienen con la empresa y se centran en las condiciones de esta de no tener dentro de su objeto social la negociación de activos de inversión. Los activos fijos que se han obtenido en la empresa pueden entenderse a favor del aumento de los ingresos, pero se analizan como una actividad de inversión particular que no se entiende como una actividad ordinaria o propia del negocio.

En todas las sentencias analizadas es posible determinar que el Consejo de Estado, en consonancia con la legislación, ha mantenido los ingresos por concepto de venta de activos fijos alejados de los gravámenes del impuesto de industria y comercio, en todo momento se ha mantenido como tesis principal que estos ingresos no se consideran gravados por este impuesto.

No obstante, el conflicto que se presenta para la determinación de los ingresos como gravados o no surge de su percepción como ingresos producto de la venta de activos fijos por parte de las entidades administrativas. El principal problema se refiere a la posibilidad de que se llegue a demostrar que el ingreso no constituye un ingreso por dividendos.

En ningún momento queda totalmente claro qué prueba se considera vital para determinar que la empresa cuenta o no con ingresos obtenidos por activos fijos debido a que en múltiples casos los conceptos de activos fijos se cruzan con las evidencias obtenidas por la empresa de sus contadores o de la forma como se consideran en los estados financieros y contables, o incluso en la Cámara de Comercio, casos en los que el Consejo de Estado no pasa a considerarlos como activos fijos y procede a gravarlos.

La Sentencia 12299, del caso Lloreda Grasas S.A. vs. DIAN, se trata de los activos fijos que tiene la empresa con el fin de obtener ingresos por estos. La empresa tiene dentro de sus activos inversiones en otras compañías que le permiten percibir ingresos de sus actividades. Una vez se analizan estos activos se deja claro que el objeto de la empresa es mantenerlos dentro de su patrimonio con el fin de que los mismo no se vendan, sin embargo, lo que establece el Consejo es que la Ley 14 de 1983 tiene como objeto grabable "todas" las actividades realizadas por la empresa, lo que permite determinar que no deben excluirse los ingresos aun cuando los mismos correspondan a activos excluidos, como es el caso de los activos fijos. Se determina que todos los ingresos obtenidos por la empresa deben ser incluidos dentro de aquellos que deben ser declarados en el impuesto de industria y comercio sin tener como hecho determinante que los mismos surjan de activos fijos o móviles. 
La Sentencia 13058, correspondiente a Delima y Cía. Medellín Ltda. vs. Municipio de Medellín, da una visión más sencilla de las intenciones de la empresa y su objeto social. No se entra a analizar el tiempo que la empresa ha tenido las acciones, sino la intención del certificado de revisoría fiscal en la que se alega que estas son "inversiones" por lo que se sobreentiende la temporalidad de las acciones y la voluntad de permanencia. Esta opinión no es muy aceptada y se entiende la necesidad de dar una mayor razón para determinar la intención de que sea un activo fijo. Ejemplo de lo anterior es la problemática en términos contables (no tributarios o legales) que el tribunal en su sentencia dice que debe sobrepasarse para la determinación de la venta de activos fijos. La empresa debe demostrar, no solo con el certificado de representación y de revisoría fiscal, su intención de mantener las acciones de activos fijos puesto que la revisoría solo indica como reconoce el bien la empresa, no da su opinión o su voto en este proceso. Aunque al final el Consejo de Estado revoca esta sentencia es importante anotar la visión del Tribunal como una de las dudas que surgen a nivel legal de la forma clara como debe demostrarse que una acción es un activo fijo.

En el caso de Aseguradora de Vida Colseguros S.A., la empresa, además de enfrentar a la Administración en los cargos de los términos que expiden los emplazamientos de la corrección, tiene una disputa por las acciones con las que esta cuenta como activos fijos mientras desarrolla una actividad mercantil. Las acciones que entran en disputa son parte de la empresa y se tienen en cuenta para un proceso de reorganización empresarial (Sentencia 13058).

Las acciones son activos fijos de la empresa y son vendidas como una forma de engrosar el patrimonio de una de las compañías del grupo empresarial. La sociedad busca mantener el control de las acciones que tiene y las vende de acuerdo con el giro ordinario del negocio y en relación con su objeto social. El proceso de venta de las acciones termina a favor de la empresa considerando que las acciones pueden ser vendidas dentro del mismo grupo empresarial.

Una de las primeras sentencias en el sentido de temporalidad a la que se enfrenta la sociedad Inversora 2010 S.A. (Sentencia 16054), una de las empresas de Grupo Bolívar S.A. y que posteriormente pasará a marcar la línea jurisprudencial bajo la que se empiezan a llevar las sentencias mostradas por la empresa Bolívar S.A. incluye la venta de acciones por parte de tres empresas pertenecientes a este grupo. Dentro de las tres empresas se toma en cuenta la observación de que "la intención que se tiene al momento de la adquisición y el tratamiento que se dé al bien durante su posesión determina la naturaleza del activo". Esta expresión lanzada por la demandante puede ser cierta en parte, se considerará la intención del bien, sin embargo, para poder determinar que el bien sea de carácter temporal o permanente va guiado por el tiempo que la empresa determina permanecer con él.

Como medio de prueba en los casos se tienen los certificados de revisoría fiscal y los balances generales, pero los hechos determinantes en esta sentencia son los tiempos que han permanecido los bienes dentro de la empresa. Podemos concluir que el tema clave en la determinación de si un bien es o no un activo fijo pasa a ser el tiempo que la empresa 
tiene el bien dentro de su patrimonio. No por esto quiere decir que la temporalidad del bien es el único elemento que se tiene en cuenta en este caso, sino además la intención con la que se adquirió el bien, la contabilidad de este y el objeto social de la empresa.

En un sentido diferente, en la Sentencia 16789, Sociedad Bolívar S.A. vs. DIAN, se realiza un análisis sobre lo que se considera un activo fijo dentro de la normativa tributaria y comercial. Se retoma el concepto de que los activos fijos deben tener una intención de permanencia en el patrimonio de la empresa por un periodo superior a dos años. En esta sentencia se refieren a las inversiones obtenidas por la empresa Inversiones Anagrama, que hace parte del Grupo Bolívar. La empresa obtiene estos ingresos y no los toma dentro de los ingresos declarados por el impuesto de industria y comercio. La sentencia analiza la información emitida por el revisor fiscal, así como los estados financieros de la compañía, y es notable que la misma tiene como intención que los bienes obtenidos como inversión se conserven en su patrimonio y permanezcan por más de dos años. En esta sentencia, el tiempo cobra especial relevancia pues indica que dependiendo del lapso que permanezca un activo se determina la intención de la empresa de mantenerlo. No dependiendo de la determinación que la empresa da del concepto que se le da al activo, es decir que la empresa lo considere como fijo o móvil, sino que además la empresa actúe frente a este bien como tal y no decida venderlo en un periodo inferior a dos años.

En este año se presenta una segunda sentencia por parte de la empresa Bolívar S.A. vs. DIAN (Sentencia 16789), con elementos muy parecidos a los anteriormente analizados. En esta sentencia la empresa Bolívar se describe como una compañía holding, de la que Inversora Anagrama hace parte en el momento de la venta de sus acciones. Es interesante anotar que el precedente, dadas las diferentes sentencias emitidas con base en el impuesto de industria y comercio de la misma demandante, cobra gran relevancia al tomar una decisión muy parecida y explicando de igual manera el motivo por el que se alejan de la decisión que se toma en la sentencia de Inversiones Anagrama. En esta sentencia se tienen en cuenta el objeto social, la certificación del revisor fiscal y el estado financiero de la empresa y en todos estos momentos se toma en cuenta la opción de comprar bienes con el fin de que se mantengan como activos fijos en su patrimonio y no sean vendidas. Esta decisión de mantenerlos permite que se tengan como activos fijos de acuerdo con lo establecido en el artículo 60 del Estatuto Tributario.

La Sentencia 16967, del 4 de marzo de 2010, cuenta con la particularidad de que a pesar de ser una demanda presentada por una entidad sin ánimo de lucro, esto en ningún momento se entra a estudiar como un hecho determinante para efectos de análisis del gravamen de los ingresos por dividendos como agregados a la base gravable del impuesto de industria y comercio. Solo entra a estudiarse si las acciones son consideradas como grabadas por el impuesto de industria y comercio. La sentencia revisa los periodos gravables de la sociedad Centro de Estudios Ganaderos y Agrícolas (CEGA) vs. Secretaría de Hacienda, sociedad que basa su actividad social en el estudio de los desarrollos políticos y económicos de la agricultura y ganadería a nivel nacional e internacional. La sociedad presenta dentro de sus actividades la adquisición de unos bonos de acciones del Banco Ganadero, 
así como acciones. Posteriormente, se ofreció la posibilidad de adquirir nuevas acciones del Banco Ganadero. En 1998, de acuerdo con lo informado, se presenta la posibilidad de venta de las acciones, que la sociedad acepta. Las acciones que se encuentran en estos casos se ven unidas a la necesidad que tiene la sociedad de hacer un uso debido de las donaciones e ingresos que recibe y el incremento de su patrimonio que permite que la misma cuente con recursos para mantener sus actividades.

Adicional a este aspecto es posible analizar como base de muchas de las sentencias estudiadas que, “de conformidad con el artículo 20 del Decreto 2053 de 1974, las acciones que se adquieren y no se enajenan dentro del giro ordinario de los negocios del contribuyente son activos fijos. Las acciones que se enajenen dentro del giro ordinario de los negocios son activos movibles" (CEGA [16967], 2010). La sociedad argumenta que las acciones de este caso se encuentran contabilizadas y adquiridas para ser tratadas como activos fijos de la empresa, en ningún momento como actividad económica o del giro ordinario de los negocios como alega la Secretaría de Hacienda.

Por otro lado, Valmiera Enterpreise Corp. y Cía. S. en C. (Sentencia 17339) discute con la Secretaría de Hacienda y la Dirección Distrital de Impuestos la inclusión de ingresos en el impuesto de industria y comercio. Alega la empresa que los bienes vendidos -que la Dirección intenta incluir dentro del impuesto de industria y comercio- corresponden a bienes que están en el activo fijo de la empresa y han permanecido por un periodo de 3 y 4 años en el patrimonio. Además, que el objeto social de la empresa permite la compra y venta de acciones, pero no por esto es su actividad comercial.

El Distrito se apoya en el argumento de que no se demuestra la calidad bajo la cual la empresa tiene los bienes, y pasa a gravarlos basándose en el objeto social de la compañía, el cual le permite la inversión y venta de acciones en cualquier medida.

El Consejo de Estado resuelve la disputa indicando que la inclusión en el objeto social de una actividad no pasa a determinarlo como del giro ordinario de los negocios, la empresa debe adquirir y enajenar acciones dentro de dicho giro para poder darle esta característica a los bienes. Como se dijo en varias sentencias y se ha mantenido como precedente, el objeto social de la empresa apoya la permanencia de estas en el patrimonio, no como intenta hacerlo ver la Administración e incluirlos en el giro ordinario de los negocios.

Ahora bien, con base en los pronunciamientos del Consejo de Estado se puede determinar que las acciones son consideradas como activos fijos.

De acuerdo con la Sentencia 18222, Promotores de Inversiones Arroba S.A. vs. DIAN, el desarrollo de actividades económicas que dentro del giro ordinario de los negocios lleven a considerar que el objeto primario y las actividades alrededor de la empresa están relacionadas con la actividad inversionista no permite que se cree un vínculo que elimine los activos fijos de la declaración de impuestos de industria y comercio considerando que la empresa en este caso se dedica a comercializar con los activos no a mantenerlos dentro de su patrimonio, como legalmente se esperaría.

La Sentencia 18703, que resuelve la controversia entre Inversiones Zárate Gutierres y Cía. S.C.S. y la DIAN, tiene en cuenta que en el proceso de los activos fijos es posible 
observar que la empresa reconoce la permanencia, objeto social y contabilización de las acciones, apoyada además por el Ministerio Público el cual muestra que el periodo en el que se conservaron las acciones es de 2 a 15 años. El Consejo de Estado toma en cuenta en todos estos procesos la intención de adquisición de la empresa y la contabilización de las acciones. Por tanto, es posible concluir que la ley excluye la venta de activos fijos en la base gravable.

Bavaria S.A. vende acciones e inmuebles que están enajenados como activos fijos, sin embargo, la Secretaría de Hacienda Distrital de Bogotá ha anotado que legalmente no existe una norma en la que se indique que los dividendos y las utilidades se encuentran excluidos. El Ministerio Público, por su parte apoya, la decisión de la demandante indicando que es evidente la intención de permanencia que tienen los activos en disputa. El Consejo de Estado en este caso continúa en todo momento con su precedente de que los ingresos por la venta de activos fijos están excluidos de la base gravable del impuesto de industria y comercio cuando no se enajenen dentro del giro ordinario de los negocios.

La empresa Nuefari S.A., en liquidación, en todo momento defiende que los activos fijos, cuando puedan entrar a definirse como tales, no deben ser gravados por el impuesto de industria y comercio. En caso de que no se entiendan como activos fijos es que deben ser gravados teniendo en cuenta el objeto social de la empresa y sus actividades de negocio (Nuefari S.A. vs. Sectraría de Hacienda de Bogotá).

Las sentencias que se estudiarán en este caso corresponden a la empresa electrificadora de Bucaramanga. Se analizarán tres sentencias por el parecido que tienen las empresas en sus hechos, partes y tiempo. Las sentencias son: 20768, Electrificadora de Santander S.A. vs. Municipio de Santander S.A. E.S.P. del 11 de mayo de 2017; 21036, Electrificadora de Santander S.A. vs. Municipio de Santander S.A. E.S.P. del 18 de mayo de 2017; y 21918, Electrificadora de Santander S.A. vs. Municipio de Santander S.A. E.S.P. del 29 de junio de 2017.

En este caso, la empresa justifica que sus activos fijos han sido vendidos con el fin de obtener ingresos que le permitan realizar un cambio en los equipos que requiere para prestar este servicio. La electrificadora indica que los activos son fijos, sin embargo, el Consejo de Estado decide que la empresa debe realizar el cambio de los bienes con el fin de poder prestar un buen servicio a sus clientes de acuerdo con las exigencias de la empresa. Este tipo de prestaciones no se relacionan con un hecho que le permita a la compañía omitir el gravamen de los bienes. La empresa está en la obligación de prestar los servicios, por tanto, no se requiere solo la contabilización que le da la empresa a los bienes, sino también la intención con la que estos fueron comprados y es evidente que en este caso la venta y adquisición se refiere a los inventarios de la empresa puesto que los bienes en discusión se dan para permitir la prestación del servicio. En este caso, para el Consejo de Estado, la Electrificadora de Santander, considera que los bienes deben ser gravados, por tanto, revoca parcialmente la sentencia del Tribunal Administrativo de Santander.

Podemos concluir que las acciones desarrolladas por las empresas cuando manejan activos fijos no son gravadas por el impuesto de industria y comercio, sin embargo, la 
empresa debe asegurar que las actividades que se realicen corresponden a activos fijos y no a su objeto social o al giro ordinario de los negocios de inversión.

\section{C. Ánimo de lucro y exenciones tributarias}

Las entidades sin ánimo de lucro han sido creadas, según la ley tributaria, para desarollar actividades de interes social.

La ley excluye de la base gravable del impuesto de industria y comercio ciertas actividades que se encuentran de forma expresa en la ley. Así, solo las actividades que se encuentran expresamente excluidas en la ley pueden optar por el beneficio de no ser parte de los sujetos pasivos del impuesto de industria y comercio.

\section{ENTIDADES SIN ÁNIMO DE LUCRO}

La jurisprudencia, en el caso de las entidades sin ánimo de lucro que pueden ser gravadas con el impuesto de industria y comercio, tiene una posición clara del proceso. Esta, a pesar de haber tenido fallos a favor o en contra de fundaciones y su obligación de pagar, en todo momento ha mantenido los mismos estándares y lineamientos claros para decidir si se es o no sujeto pasivo del gravamen.

El primer punto para analizar es la exclusión de las actividades sin ánimo de lucro de las entidades en la Ley 14 de 1983. Dicha ley, en su artículo 39, señala: “d) La de gravar con el impuesto de Industria y Comercio, los establecimientos educativos públicos, las entidades de beneficencia, las culturales y deportivas, los sindicatos, las asociaciones de profesionales y gremiales sin ánimo de lucro, los partidos políticos y los hospitales adscritos o vinculados al sistema nacional de salud".

Volvemos a llamar la atención del artículo, ahora en la opción de qué entiende el Consejo de Estado y en dónde se enmarcan estas entidades sin ánimo de lucro, porque es claro que el concepto de beneficencia que mantiene la ley y que puede verse en la RAE de: "Conjunto de instituciones y servicios de ayuda a los necesitados" (RAE, 2019), se refiere exclusivamente al apoyo de personas poco favorecidas o que no tienen recursos suficientes para cubrir sus necesidades básicas.

\section{MERCANTILIDAD DE LAS FUNDACIONES}

La mercantilidad de las operaciones se refiere a la permeabilidad de las actividades comerciales frente a las actividades civiles. Es decir, a pesar de que las entidades sean sin ánimo de lucro esto no evita que una entidad realice actividades comerciales. El proceso de mercantilidad se ve en las fundaciones en las que en todos los casos se van presentando dudas sobre su desarrollo. 


\section{a. Sentencias}

En el caso de la Fundación Carulla (Sentencia 17552), se le reprocha el manejo de recursos. Sin embargo, en esta sentencia se procede a determinar que no son totalmente equiparables las actividades comerciales a las civiles, así como tampoco pueden ser tomadas como iguales las "empresas civiles" o comerciales. Es claro para la jurisprudencia que las sociedades no pueden ser equiparadas en el ánimo de lucro pues lo que diferencia las actividades es la reinversión que tiene la Fundación en pro de su actividad y no a favor de sus socios. Así mismo, marca la pauta determinante el que las sociedades sin ánimo de lucro pueden tener las acciones dentro de su patrimonio pues no es excluyente un posible aumento de capital por parte de la Fundación puesto que esto ayuda a que la labor realizada por la empresa pueda ser sustentable. El cumplimiento del objeto social de la empresa se encuentra enmarcado en la posibilidad de mantener su patrimonio. La Fundación recibe donaciones y acciones para aumentar su capital, que pasa a ser la disputa de la Secretaría de Hacienda, pero el manejo de las acciones no es especulativo, es solo para desarrollo del objeto social de la Fundación. Esta sentencia no permite una demarcación de la mercantilidad de la Fundación, sino que, al contrario, determina su actividad como excluida por la Ley 14 de 1983 en el sentido de considerarla actividad de beneficencia.

Centro de Estudios Ganaderos y Agrícolas (CEGA) es una entidad sin ánimo de lucro que, como su nombre lo indica, se basa en el estudio del sector agropecuario; la empresa no desarrolla actividades comerciales como lo intenta hacer ver la Administración. La empresa cuenta con la venta de activos fijos. En esta sentencia se reconoce que los ingresos por la venta de activos no se encuentran gravados, sin embargo, no se hace mayor referencia a la calidad de entidad sin ánimo de lucro de la entidad, solo a los activos fijos (Centro de Estudios Ganaderos y Agricolas - CEGA vs. Secretaría de Hacienda).

Por otra parte, en la entidad sin ánimo de lucro la empresa tiene el objeto social de realizar actividades de optimización tecnológica. La venta de las acciones hace parte del giro ordinario de los negocios. Sin embargo, en la Sentencia 17002, Asociación para la Sistematización Bancaria - ASOBAnCARIa vs. Secretaría de Hacienda, la Administración dice que se trata de una empresa, no de una fundación, pues no tiene desarrollados los intereses comunes de la fundación. La ley busca, en este caso, dar beneficios a las asociaciones culturales e intelectuales, esta decisión no es requerida para todas las asociaciones.

En esta sentencia, la consideración de la sala indica que las asociaciones gremiales cuentan con la prohibición de ser gravadas, pero las actividades llevan una intención de ánimo de lucro y en ningún momento la Asociación demostró que las acciones se encontraran dentro del activo fijo, así como tampoco percibe las condiciones bajo las cuales fueron vendidas las acciones y, por tanto, es importante la posible mercantilidad de las fundaciones, como en este caso. Por esta razón, los ingresos deben ser gravados.

La Comunidad Universidad Javeriana - Compañía de Jesús es una persona jurídica reconocida, que no tiene relación con la Universidad Pontificia Javeriana, que se dedica a la celebración de actos litúrgicos y apoyo a las personas. La comunidad, sin embargo, 
no celebra contratos. No obstante, aquí se mantiene la posición de la mercantilidad que tienen las entidades sin ánimo de lucro, es decir que pueden ser gravadas las actividades comerciales que estas realizan. Para el Consejo de Estado este es uno de esos casos puesto que se pueden realizar actividades comerciales por ser una persona jurídica, y el factor bajo el que se da la calidad de comerciante aplica solo a las personas naturales, no jurídicas. Por lo anterior se considera gravada con impuesto de industria y comercio la actividad de la entidad (Sentencia 17881, Comunidad Universidad Javeriana - Compañía de Jesús vs. Secretaría de Hacienda).

La Sentencia 18263, respecto de la Fundación Social, aclara que la obligación de declaración y pago del impuesto de industria y comercio no se genera por la naturaleza jurídica de la Fundación, sino por la realización de actividades que se entienden como comerciales y deben ser gravadas con el impuesto de industria y comercio.

Es interesante notar que en este caso la mercantilidad de la empresa no se pone en cuestionamiento directo, la Fundación no tiene dentro de su objeto social la realización de actividades mercantiles, pero es evidente para el Consejo que las actividades que lleva a cabo con el fin de poder mantener su patrimonio y desarrollar su objeto social es lo que pasa a determinar la obligación de declarar y pagar impuesto de industria y comercio por los ingresos de las actividades comerciales realizadas dentro de un territorio. Desviando esta situación de la percepción inicial de exclusión de las fundaciones por ley y su condición de sociedad civil que no realiza actividades comerciales gravadas.

En el caso de la Sentencia 17364, de la Fundación San Antonio, se ve una mezcla de los conceptos que se vienen analizando en las sentencias emitidas en una situación parecida. En este momento, se mantiene el reconocimiento de que la obligación de declarar y pagar el impuesto de industria y comercio no se determina por la naturaleza jurídica de la fundación, sino por la posibilidad de realizar actividades gravadas por el impuesto que la obliguen como sujeto pasivo del mismo dentro del territorio en el que se desarrolle la actividad gravada. El gravamen de la actividad se dará en caso de que la misma se encuentre como una actividad gravada, siempre teniendo en cuenta que las actividades que se entienden como excluidas no estarán enmarcadas dentro de los ingresos por ser agregados a la posible declaración del impuesto de industria y comercio. Adicionalmente, se encuentra que las actividades desarrolladas por la fundación son variadas y abarcan procesos de minería, cantera y actividades de inversión y obtención de dividendos. Respecto a las actividades de dividendos se mantiene el precedente de que las actividades de percepción de venta de activos fijos no son per se gravados por el impuesto y se consideran rentas pasivas. A pesar de la combinación de precedentes se decide que los ingresos de la Fundación no se encuentran gravados.

El segundo caso que se presenta ese mismo año por la Fundación Social es la Sentencia 18277, fallada por el consejero ponente William Giraldo Giraldo, y a pesar de la similitud del caso con la primera sentencia que se estudió de esta Fundación, las determinaciones son un poco diferentes. Esta sentencia, a diferencia de la primera, no causa tanta 
impresión, no es tomada como una sentencia hito, ni entra a hacer un estudio tan amplio del impuesto de industria y comercio en los procesos de dividendo.

Esta sentencia estudia su objeto social, luchando con la idea de asistencialismo que mantiene la Dirección de Impuestos y Aduanas Nacionales (DIAN) y que ya pasa a ser considerada como arcaica por las fundaciones. Además del mantenimiento del Consejo de Estado del concepto de activos fijos como no gravados por el impuesto. Así mismo, se maneja la idea de que el numeral 5 del artículo 20 del Código de Comercio refiere a la creación de empresas con el fin de que se generen dividendos y aumentar las ganancias, pero en este caso ni su objeto social ni el desarrollo habitual de la empresa se centra en las compañías o acciones y, por tanto, solo pueden entrarse a considerar los activos fijo como no gravados en el mismo sentido. Este caso mantiene la idea que prima en el Consejo de Estado y que se comparte que dice que, si se realizan actividades gravadas por el impuesto a pesar de su naturaleza, deben gravarse.

La última sentencia para estudiar de la Fundación Social, la 18383, mantiene la intención de que no sean gravadas las acciones puesto que es una entidad sin ánimo de lucro que no realiza actividades mercantiles. Y en caso de realizar estas actividades, las mismas no tienen el ánimo de ser realizadas como actos de comercio o para generar ganancias para los dueños o accionistas de la Fundación.

El Consejo, sin embargo, mantiene la decisión de que las entidades sin ánimo de lucro, a pesar de desarrollar estas actividades no se transforman en comerciales, y mantiene la decisión de no gravar los ingresos o dividendos basado en que las entidades utilizan estos recursos para mantener su patrimonio.

La Fundación Otero de Francisco y María Liévano de Otero (sentencia 18128) tiene conflictos debido a que la sociedad no ha declarado el impuesto de industria y comercio, considerando que las entidades sin ánimo de lucro están exentas de la declaración. Además, los dividendos y activos fijos son rentas de naturaleza pasiva no sujeta al impuesto. La Administración sostiene la posibilidad de mercantilidad de las entidades sin ánimo de lucro. No obstante, el Consejo de Estado da prioridad al manejo de recursos y la repartición de las ganancias entre los asociados, sin embargo, la entidad decide que las ganancias son reinvertidas en pro de la actividad.

La última sentencia para analizar en el caso de fundaciones se refiere a la sentencia 18663 del Seminario Consular de Bogotá, y tiene que ver con las actividades propias de estudios sacerdotales, para el sostenimiento y manejo de su objeto social: la Fundación. La Fundación tiene dentro de su entidad dividendos por activos fijos. El aspecto básico de la demanda requiere informar los ingresos obtenidos por la entidad dentro de las condiciones del artículo 20 numeral 5 del Código de Comercio. En una parte se refiere a los inmuebles que proporcionan ingresos por los arrendamientos. La sentencia en este caso decide que los inmuebles no se encuentran dentro de los ingresos gravados por considerar que estos no son gravables pues se entienden como rentas pasivas que no constituyen como tal una actividad comercial, industrial o de servicio, así como las otras actividades que la empresa 
refiere no son gravables pues son utilizadas para el desarrollo de los objetos sociales de la Fundación.

¿Es gravada con impuesto de industria y comercio la actividad de entidades sin ánimo de lucro?

En las figuras 3 y 4 podemos ver, en primer lugar, la distribución de la decisión del Consejo de Estado; se observa también cómo se mueve entre las decisiones de gravar o no con el impuesto de industria y comercio las actividades desarrolladas por las entidades sin ánimo de lucro y cómo algunas son gravadas parcialmente identificando los hechos específicos de cada uno de los casos. Estas figuras remiten directamente a la mercantilidad de la entidad sin ánimo de lucro, no al fallo sobre dividendos.

Igualmente, se observa cómo dentro del periodo analizado solo las sentencias que se posicionan en los extremos temporales toman como no excluidas las actividades realizadas por la Fundación. Mientras que también tienen una posición relevante en este caso y muy atada al título del apartado que es la mercantilidad de las fundaciones. En este caso, el Consejo de Estado determina que si bien es cierto la necesidad de que las fundaciones es el mantenimiento y posible aumento de sus recursos para poder sostener el desarrollo del objeto social, muchas de estas actividades que realizan pasan a ser económicas y la ley no excluye estas actividades por la naturaleza de la entidad, pues en los casos analizados en el momento en que se trata de activos fijos se mantiene la negativa de eliminar su cobro. No obstante, el desarrollo de actividades comerciales sí lo encuentra unido a la Ley 14 de 1983 y determina que el desarrollo de una actividad gravada convierte a la persona natural y jurídica en sujeto pasivo de la actividad.

Figura 3. ICa en entidades Sin ÁNimo de LuCro 1

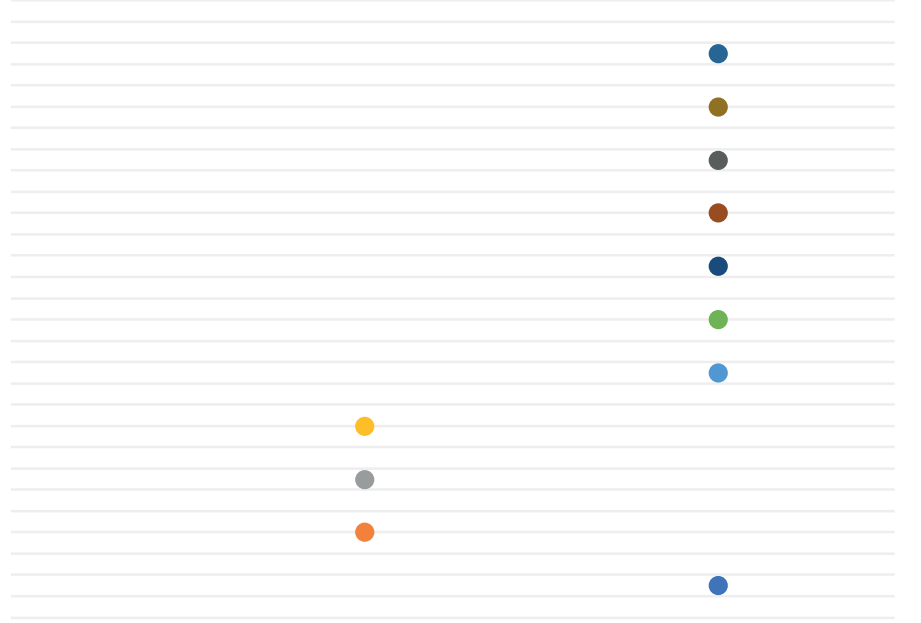

Obligado
No obligado
- Fundación Carulla

- CEGA

- Servibanca

- Comunidad Javeriana

- Fundación Social

- San Antonio

- Fundación Social (sep.)

- Fundación Social (nov.)

- Fundación Social (feb.)

Otero

- Seminario Conciliar

Fuente: Ministerio de Hacienda. 


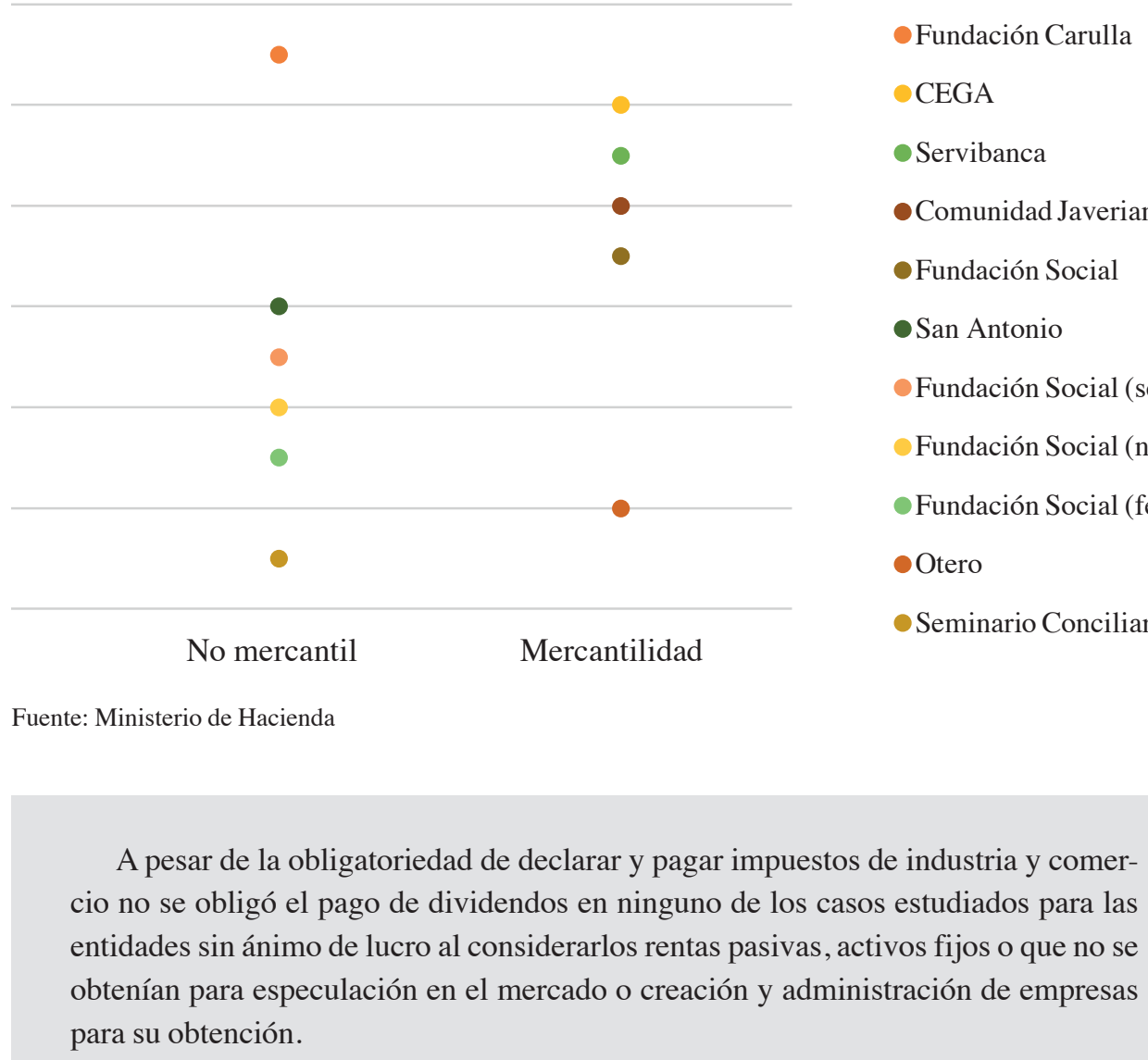

Podemos decir, entonces, que la naturaleza de la fundación no determina su exclusión del impuesto de industria y comercio, pero sí permite que mantenga, en caso de ser sujeto pasivo del derecho, la posibilidad de sacar como ingresos gravados los correspondientes a dividendos, pues, en ningún caso se probó el desarrollo del numeral 5 artículo 20 del Código de Comercio. Ninguna de las entidades creó empresas con el fin de obtener lucro de sus dividendos de manera activa y comercial, simplemente se beneficiaban de sus ingresos como renta pasiva para mantener su renta y patrimonio. El hecho de mantener rentas pasivas no constituye una actividad comercial, industrial o de servicios que pueda ser entendida como gravada por el impuesto de industria y comercio.

\section{b. Compilado}

¿Es gravado un ingreso por dividendos por el impuesto de industria y comercio? 
Figura 5. Gravamen dividendos en iCa 3

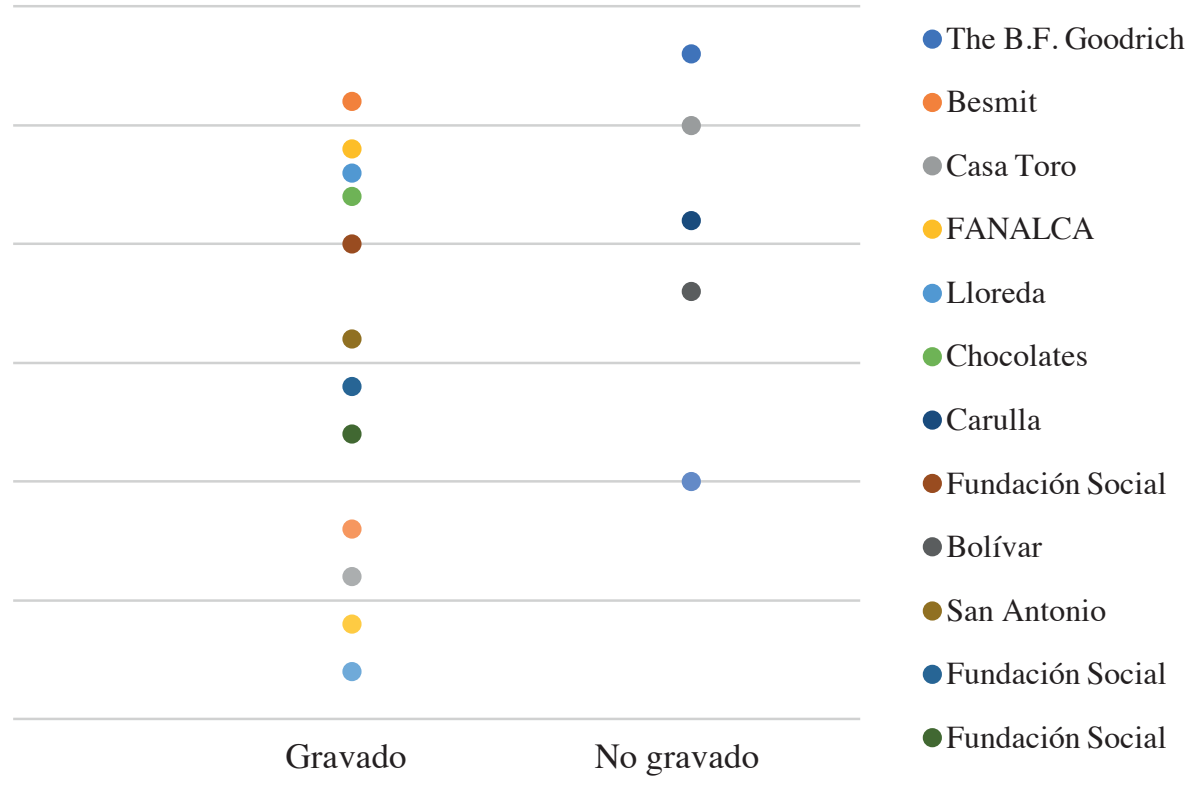

Fuente: Ministerio de Hacienda.

\section{Conclusiones}

Como conclusiones de este estudio podemos señalar, en primer lugar, que el análisis de la Ley 14 de 1983 muestra que las normas y reformas tributarias a las que se ha tenido que enfrentar constantemente Colombia no afectan de una manera tan directa lo contemplado en la normativa como posiblemente se esperaría.

La Ley 14 de 1983 está vigente, con solo unos pequeños ajustes que han pasado a ser determinantes como caballos de batalla de la Administración de Impuestos para el aumento del recaudo, no por esto es una posición que todos los contribuyentes compartan o que incluso en mismo Consejo de Estado comparta. Las diferentes anotaciones a la ley han continuado a lo largo del tiempo y han soportado y ratificado la primacía de lo establecido en esta sobre las demás decisiones. La determinación de sujetos pasivos y activos, así como las actividades y exenciones se encuentran claramente establecidas y, a pesar de que se tome como base para los lineamientos lo establecido en el Estatuto Tributario y en el Código de Comercio, es evidente que la ley no acepta modificaciones de estas normas.

Lo determinado en el Estatuto Tributario respecto a los activos fijos se encuentra establecido en la ley y ha sido respetado a rajatabla por el Consejo de Estado, lo que es un hecho de admirar pues en ningún caso se ha puesto en duda la fuerza de la norma en decir que esos activos no se encuentran gravados. En cuanto al numeral 5 del artículo 20 del Código de Comercio sí se presentan mayores dificultades debido a la ambigüedad de la interpretación de las leyes y la normatividad como sustento de lo que se entiende como 
norma en este artículo. Se puede decir que el artículo marca la base para la normativa, pero es claro que no es este el que termina determinando los elementos del impuesto.

\section{Figura 6. Gravamen dividendos en iCa 4}

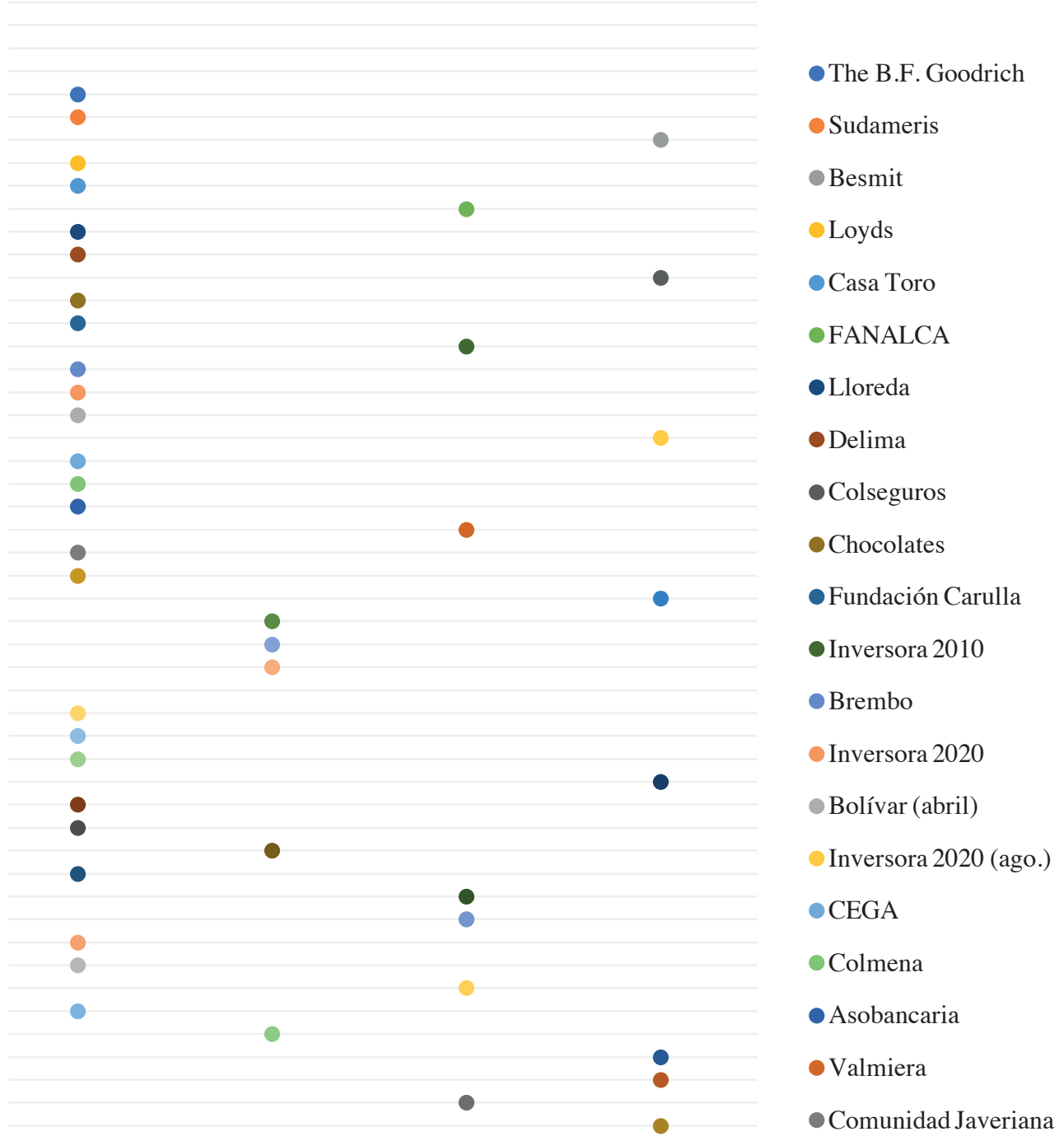

Excluido

Gravado

Fuente: Ministerio de Hacienda

La Ley 14 de 1983, al final, cuenta con todos los elementos correctamente determinados que influyen en las decisiones de la administración judicial y tributaria sobre los ingresos gravables del impuesto de industria y comercio. 
En cuanto al giro ordinario de los negocios y el objeto social se crea un entramado que los une a lo que determinen las empresas como activos fijos. Es claro que el objeto social de la empresa y el giro ordinario de los negocios empieza a tener prioridad en los primeros años en los que se analiza la empresa como la inversora. Los primeros casos, sin embargo, se remitían a los conflictos del giro ordinario de las empresas cuando estas eran extranjeras y pasaban a tener inversiones en Colombia. En este caso, el tratamiento como empresas con rentas pasivas desviaba la intención de la Administración en el cobro del impuesto.

No es claro en ningún momento en qué casos exactamente una empresa tiene como objeto social o dentro del giro ordinario de los negocios esta actividad, pues todas estas pasan a verse mezcladas con los activos fijos de las empresas que, como se mostró en el documento, en todo momento se consideran como exentos del gravamen y eso no es discutido. Lo que pasa a ser discutido, entonces, es la intención y la temporalidad con que las empresas tienen los bienes. Lo relevante pasa a ser cuándo una empresa pasa a decir que los bienes son activos fijos o móviles de acuerdo con el artículo 60 de Estatuto Tributario.

Pero esto no quiere decir que no existan conflictos con los activos fijos. En muchos casos el Consejo de Estado y la Administración ponen en duda que las empresas cuenten con los bienes y los reconozcan como activos fijos. Muchos de los casos pasan a ser decididos por la intención que tuvo la empresa al momento de adquirirlos, a lo que se suma la permanencia de los bienes dentro del patrimonio de la compañía y la intención de que estos continúen generando ingresos en su calidad de rentas pasivas.

Al final vemos una de las dificultades de la norma que es el tratamiento de las actividades sin ánimo de lucro. Aunque en muchos casos se decide que las entidades sin ánimo de lucro no son gravadas se dictamina como primacía de la calidad comercial sobre la civil que las entidades con y sin ánimo de lucro cuentan con una obligación de continuación de la mercantilidad de las actividades que desarrollan.

Las sentencias muestran que las entidades sin ánimo de lucro tienden a no se gravadas con el impuesto de industria y comercio sobre los ingresos por dividendos porque se entiende que, en muchos casos, estos ingresos o bienes corresponden a obligaciones que tiene la entidad y están atados a la necesidad de las entidades sin ánimo de lucro de mantener su patrimonio de manera que puedan continuar prestando los servicios sociales para los que fueron constituidas.

Es posible concluir, como análisis del tema, que existen lineamientos poco delimitados del gravamen de industria y comercio en cuanto a los ingresos por dividendos. Muchas de estas sentencias mantienen un mismo lineamiento jurisprudencial hasta el momento en el que se presente un cambio de magistrado en el proceso de decisión. No es normal en estos casos ver cambios jurisprudenciales amplios por hechos marcados por la sentencia; es posible, entonces, no considerar cambios legales importantes respecto de la normativa.

Los cambios más notables se refieren a los temas que se han venido tratando a lo largo del trabajo. La percepción es que el conflicto del gravamen de los ingresos por dividendos con motivo del objeto social de la empresa es un conflicto que no cerrará en ningún momento. El conflicto se basa en el sentido que tienen las capacidades de las empresas, pero 
pasando por la discusión básica de que aquellas que inician un tratamiento de sas cuentan con una desventaja frente las demás empresas.

El giro ordinario de los negocios puede ser una de las líneas determinantes, aunque al final lo que haga la empresa en dicho giro choca con la idea de temporalidad y profesionalidad que, como se anotó en el documento, no corresponde a la visión del Consejo de Estado. La especialidad de lo contenido en la Ley 14 de 1983 corresponde a la guía de profesionalidad y temporalidad en los procesos de gravamen. Se entiende que la temporalidad y el giro ordinario de los negocios se relaciona con las empresas que desarrollen estas actividades para que puedan tomarse en cuenta las diferentes funciones de estas. Este argumento, entonces, se basará en lo que presente la empresa como actos dentro del giro ordinario de los negocios y es uno de los argumentos que pueden marcar o no el gravamen, principalmente por la falta de tiempo que la empresa necesita para encontrarse como sujeto pasivo. En este caso lo mejor es mirar los procesos dentro del marco de los activos fijos o asumir el desarrollo de una actividad comercial gravada.

Así, es posible concluir que los ingresos por concepto de dividendos no son gravados y no deberían ser gravados en la mayoría de los casos. En primer lugar,

... se define lo que se debe entender por rentas pasivas y en el numeral cuarto se refiere a los ingresos provenientes de la enajenación o cesión de derechos sobre activos que generen rentas pasivas. Sobre este particular, es necesario establecer que los activos que generan rentas pasivas son aquellos que generan cada uno de los ingresos mencionados en el artículo 884 del Estatuto Tributario. Ejemplo de ello, son las acciones respecto de los dividendos, los bonos respecto de los intereses, los inmuebles respecto del arrendamiento, entre otros conceptos. (DIAN, Concepto 19320)

Dentro de estas rentas encontramos los dividendos, los cuales se entienden como ingresos obtenidos sin el ejercicio de actividades comerciales, industriales o de servicio que puedan ser gravadas directamente por el impuesto de industria y comercio.

Las rentas pasivas son entendidas por el Consejo de Estado en un ámbito grupal, en el que en muchos casos se habla de las rentas pasivas en su totalidad; en este aspecto específico se puede considerar la posibilidad de extrapolar las obligaciones de gravamen de las rentas pasivas como un todo. Es decir, las rentas pasivas como ingresos que no son obtenidos al final por el ejercicio de ninguna actividad comercial, industrial o de servicios. En este sentido, cuando el Consejo de Estado habla de rentas pasivas no gravadas puede entenderse sin dudas que no deben ser gravadas en ninguna de sus opciones, todo basado en las características del impuesto y su idea de gravar las actividades comerciales, industriales y de servicio que se den en la empresa.

Es posible, entonces, concluir que con base en la falta de realización de actividades comerciales, industriales o de servicio, como lo estipula el Estatuto Tributario, como rentas pasivas no son gravadas por el impuesto de industria y comercio. 
Por otra parte, los activos fijos que posean las empresas se encontrarán excluidos del gravamen de industria y comercio.

Sin embargo, en esta área existen demasiadas zonas grises y zonas no establecidas con la suficiente claridad como para poder tener una certeza de que los ingresos deben o no ser gravados. Ejemplo de esto es la temporalidad del bien, la determinación de que se tiene un bien por un periodo superior a dos años es subjetiva y puede no determinar con la certeza y la precisión que requiere el sistema el gravamen de los ingresos. Así las cosas, la temporalidad debe ser tomada en cuenta por las entidades, pero incluso llegar a aumentar el tiempo, con este aumento es posible dejar clara la necesidad de temporalidad de las acciones, pues si una empresa considera la venta por un periodo más prolongado es posible determinar que el ánimo de permanencia del bien es mayor.

La determinación de que sean más años es igual de subjetiva que la determinación de que se establezca el límite temporal de los activos fijos en dos años; sin embargo, si se considera un tiempo mayor, como son cuatro años, es probable que se relaje la posición de la Administración por la cantidad de periodos contables que deben pasar para la venta del activo. Si el bien permanece este tiempo en la empresa puede asegurarse la permanencia basada en la pobre disponibilidad del bien en el tiempo.

Este argumento va atado a la intención de la empresa. Que una compañía diga que el bien tenía toda la intención de permanecer en su patrimonio es subjetivo, especulativo y lleva a gran cantidad de confusiones con la Administración. Esta idea de intención puede o no mantenerse en el tiempo y puede variar de posiciones y hechos tan sencillos como el cambio de gerencia o la idea de capitalización o contabilización de los activos en el tiempo, y se considera que debe ser eliminado como forma de demostrar la intención o la falta de intención de obtener ingresos.

Así mismo, la contabilización de los bienes como activos fijos puede ser tomada como prueba válida, aunando esto al tiempo que la empresa lo tenga es una forma de la Administración de limitar las solicitudes para los ingresos de dividendos. El conflicto está en los tiempos previos a los que se cumplan los cuatro años, pero es claro entonces que si no se ha vendido el activo fijo no será necesario para la administración el registro por venta, el cual es el principal conflicto presentado ante el Consejo de Estado. A pesar de que la Administración incluye la obtención de ingresos, es evidente que la mayor parte de las disputas que involucran activos fijos se debe a la venta de estos; con esto es posible cercar un poco las quejas presentadas por la Administración respecto a los bienes.

Además, es importante anotar que la contabilidad es una de las pruebas más claras que tiene la empresa para defender su intención de mantener un bien dentro de su patrimonio.

Ahora bien, es claro que existen rentas pasivas y que todas las sociedades cuentan con la posibilidad de tener dentro de sus bienes acciones. Un hecho muy diferente es tener las acciones en una compañía cuyo objeto social sea el proceso de inversión y constitución de empresas con el fin de obtener rentas, y otro que eventualmente se vendan acciones para recapitalizar la entidad u obtener un ingreso eventual. 
La diferencia de conceptos no se refiere a que la empresa tenga en su objeto social que pueda vender o negociar acciones, pues existe la posibilidad de incluir una cláusula general que habilite a realizar "todas las demás actividades que considere importantes para el desarrollo de su actividad comercial". Entonces, podemos entender que todas las empresas podrían ser gravadas con el impuesto por vender las acciones, sin importar que esté en su objeto social o no. Por ello, hay que mirar cómo lo tomen en su contabilidad, al final lo que debe entenderse es una "realidad objetiva" sobre una "realidad formal". Porque es evidente que existe una actividad económica establecida en el numeral 5 del artículo 20 del Código de Comercio que será gravada con el impuesto de industria y comercio independientemente de las consideraciones que la persona jurídica pueda tener en mente. Lo anterior reiterando el concepto enunciado en la Sentencia 23097 de 2108 que cita la sentencia 18750 del consejero ponente Hugo Fernando Bastidas Bárcenas:

... cuando la ejecución del acto de comercio previsto en el numeral 5 del artículo 20 del C. de Co., esto es, "[1] intervención como asociado en la constitución de sociedades comerciales, [...] o la negociación a título oneroso de las partes de interés, cuotas o acciones" es ocasional, dicho acto de comercio no constituye actividad mercantil gravada con este tributo, pero, cuando esta actividad se ejerce de manera "habitual y profesional" sí, caso en el cual, la base gravable del impuesto la constituye el ingreso que se percibe por concepto de dividendos pues es la forma en que se materializa la ganancia obtenida por la ejecución de la referida actividad mercantil. (Sentencia 250002327000-2008-00209-01[18750])

En cuanto a las entidades sin ánimo de lucro, se comparte la decisión de la mercantilidad que estas contienen; en el momento en que desarrollen actividades comerciales, industriales o de servicio deben ser gravadas con el impuesto de industria y comercio sin tener presente su ánimo de lucro. Toda entidad con o sin ánimo de lucro que desarrolle una actividad comercial como es la obtención de ingresos por dividendos o venta de activos fijos que generen dividendos debe ser gravada.

Esta decisión se desvirtúa por la necesidad del mantenimiento del patrimonio de las entidades; sin embargo, el marco conceptual de las Normas Internacionales de Información Financiera (NIIF) es claro al indicar que el mantenimiento del patrimonio de una empresa es una obligación de cualquier entidad con y sin ánimo de lucro. Es obligación de la gerencia y los contadores velar por que la empresa se mantenga a flote y genere los ingresos requeridos para lograrlo.

Tristemente, mi posición puede ser manchada por la visión social y política del momento en el que muchas de las entidades sin ánimo de lucro cuentan con grandes patrimonios y están exentas de impuestos por la necesidad de cubrir las falencias del Estado en la protección social y los estamentos básicos de un Estado social de derecho. Igual ocurre con las entidades sin ánimo de lucro que son usadas como fachadas para evasión de los impuestos a su cargo. Por tanto, debe hacerse un mayor control de las entidades sin ánimo 
de lucro y estas deben ser obligadas a pagar impuesto de industria y comercio cuando realicen actividades comerciales, e incluso obligarlas a pagar por ciertas donaciones y beneficios económicos que reciben, cumpliendo con otro deber social que es el sostenimiento del Estado.

Se puede concluir que en los casos de ingresos gravables con el impuesto de industria y comercio la decisión más acertada para una empresa es tomar siempre la intención y la contabilización de los bienes como activos fijos. Claro, que si la intención no es esta, se desalienta que se utilice la figura jurídica de los activos fijos para evitar el gravamen del impuesto.

\section{Referencias}

Alvarez Siota, M. (2010). Analogía e interpretación en el derecho tributario. Marcial Pons, Ediciones Jurídicas y Sociales. http://vlex.com/source/ analogia-e-interpretacion-en-el-derecho-tributario-1469

Cano Martínez de Velasco, J. I. (2012). La analogía. Derecho y lógica. Bosch.

Castro de Cifuentes, M. (2009). Derecho Comercial. Temis.

Marín Elizande, M. (2017). La estructura jurídica del tributo: el hecho generador. En J. R. Piza Rodríguez, La obligación tributaria y sus fundamentos constitucionales (p. 474). Universidad Externado de Colombia.

Osorio Vesga, S. (2017). Tibutación territorial: una deuda sin saldar. En J. R. Piza Rodríguez, El Impacto de la Ley 1819 de 2016 y sus desarrollos en el sistema tributario Colombiano (t. III, pp. 249-267). Universidad Externado de Colombia.

Parra Ortiz, H. F. (2004). El impuesto de industria y comercio. Temis.

Parra Ortiz, H. F. (2010). Análisis comparativo del impuesto de industria y comercio en Colombia. Nueva Legislación.

Piza Rodríguez, J. (2017). El impuesto de industria, comercio, avisos y tableros. En J. R. Piza Rodríguez, Los tributos territoriales en el ordenamientos jurídico colombiano. Un análisis crítico (p. 136). Universidad Externado de Colombia.

Posada García-Peña, M. (2004). Impuesto de industria y comercio. En L. Cruz de Quiñónez y A. Lewin Figueroa, La jurisprudencia tributaria del Consejo de Estado. Instituto Colombiano de Derecho Tributario. 
Quiñónez Montealegre, A. (2009). El impuesto de industria y comercio. Conflictos y propuesta de reforma. Editorial Universidad del Rosario.

Real Academia Española (RAE) (s. f.). Beneficentia. En Diccionario de la Real Academia de la Lengua. https://dle.rae.es/?id=5LwZAvg

Superintendencia de Industria y Comercio (2002). Superintendencia de Industria y Comercio.http://www.sic.gov.co/recursos_user/historico/d2011 sic6466.htm

\section{Normatividad}

Congreso de la Republica (2008). Código de Comercio.

Congreso de la Republica (2018). Estatuto tributario.

Congreso de la Republica (1983). Ley 14 de 1983.

Congreso de la Republica (2016). Ley 1819 de 2016.

Congreso de la Republica (2011). Estatuto tributario de Bogotá.

Dirección de Impuestos y Aduanas Nacionales. Concepto 19320 de 2018.

Dirección de Impuestos y Aduanas Nacionales. Concepto 19320 de 2018.

Superintendencia Financiera (2005). Concepto 20056-960, 06 de julio de 2005. https:// www.superfinanciera.gov.co/sFCant/Normativa/doctrinas2005/dividendos027.htm

\section{Jurisprudencia}

Consejo de Estado. Lloyds Bank (Blsa) Limited (antes Banco de Londres y América del Sur), Sentencia de 1 de julio de 1994.

Consejo de Estado. Sentencia 23700. Actiunidos S.A. vs. Distrito Capital. 15 de noviembre de 2018 .

Consejo de Estado. Sentencia 22452. Amalfi Botero y Cia S.A. vs. Distrito Capital. 18 de octubre de 2018.

Consejo de Estado. Sentencia 22374. Aminversiones S.A. vs. Distrito Capital. 4 de octubre de 2018 . 
Consejo de Estado. Sentencia 18222. Promotores de inversiones Arroba S.A. vs. DIAN. 23 de junio de 2011.

Consejo de Estado. Sentencia 13726. Aseguradora de vida Colseguros S.A. ESP. 22 de Septiembre de 2004.

Consejo de Estado. Sentencia 17002. Asociación para la sistematización Bancaria - AsoBANCARIA vs. Secretaría de Hacienda. 25 de marzo de 2010.

Consejo de Estado. Sentencia 4209. Banque Sudameris. 25 de noviembre de 1992.

Consejo de Estado. Sentencia 4548. Besmit vs. DIAN. 3 de marzo de 1994.

Consejo de Estado. Sentencia 9086. Casa Toro S.A. 5 de marzo de 1999.

CEGa (16967), C. d.-C. (4 de marzo de 2010). Artículo 20 decreto 2053 de 1974. Cita en la sentencia del Consejo de Estado de 22 de septiembre de 2004, Exp. 13726, C.P. María Inés Ortiz Barbosa.

Consejo de Estado. Centro de Estudios Ganaderos y Agrícolas - CEgA vs. Secretaría de Hacienda. Sentencia de 4 de marzo de 2010.

Consejo de Estado. Sentencia 17881. Comunidad Universidad Javeriana - Compañía de Jesús vs. Bogotá D.C. Secretaría de Hacienda. 16 de marzo de 2011.

Consejo de Estado. Sentencia 13058. Delima y Cía Medellín Ltda. 7 de noviembre de 2002.

Consejo de Estado. Sentencia 21776. El Zuque S.A. 31 de mayo de 2018.

Consejo de Estado. Sentencia 20768. Electrificadora de Santander S.A. vs. Municipio de Santander S.A. E.S.P. 11 de mayo de 2017.

Consejo de Estado. Sentencia 21036. Electrificadora de Santander S.A. vs. Municipio de Santander S.A. E.S.P. 18 de mayo de 2017.

Consejo de Estado. Sentencia 21918. Electrificadora de Santander S.A. vs. Municipio de Santander S.A. E.S.P. 29 de junio de 2017.

Consejo de Estado. Sentencia 10066. Fanalca. 10 de noviembre de 2000. 
Consejo de Estado. Sentencia 17552. Fundacción Carulla. 7 de octubre de 2005.

Consejo de Estado. Sentencia 17364. Fundación San Antonio. 1 de septiembre de 2011.

Consejo de Estado. Sentencia 18263. Fundación Social. 19 de mayo de 2011.

Consejo de Estado. Sentencia 18277. Fundación Social. 17 de noviembre de 2011.

Consejo de Estado. Sentencia 18383. Fundación Social vs. Secretaría de Hacienda - Dirección Distrital de Impuestos. 2 de febrero de 2012.

Consejo de Estado. Sentencia 16206. Inversiones Brembo S.A. vs. Distrito Capital de Bogotá. 4 de septiembre de 2008.

Consejo de Estado. Sentencia 16788. Inversora 2020 S.A. vs. DIAN. 13 de agosto de 2009.

Consejo de Estado. Sentencia 16790. Inversora 2020 S.A. vs. DIAN. 2 de abril de 2009.

Consejo de Estado. Sentencia 17953. Inversora Colmena S.A. vs. Secretaría de Hacienda Distrital. 26 de enero de 2010.

Consejo de Estado. Sentencia 16054. Inversora S.A., 3 de abril de 2008.

Consejo de Estado. Sentencia 18703. Inversora Zárate Gutierres y Cía. S.C.S. vs. Dirección Distrital de Impuestos. 13 de junio de 2013.

Consejo de Estado. Sentencia 18128. La Fundación Otero de Francisco y María Liévano de Otero vs. Secretaría de Hacienda - Dirección Distrital de Impuestos. 9 de agosto de 2012.

Consejo de Estado. Sentencia 12299. Lloredas Grasas. 16 de noviembre de 2001.

Consejo de Estado. Sentencia 20602. Mislo III lTDA en liquidación y Mislo II Cía. S.A.S vs. Distrito Capital. 17 de agosto de 2017.

Consejo de Estado. Sentencia 14876. Nacional de Chocolates. Estado 1 de septiembre de 2005.

Consejo de Estado. Sentencia número. Nuefari S.A. vs. Sectraría de Hacienda de Bogotá. 20 de noviembre de 2014. 
Consejo de Estado. Sentencia 18903. Organización Corona S.A. vs. Secretaría de Hacienda Distrital y Dirección Distrital de Impuestos. 16 de mayo de 2013.

Consejo de Estado. Sentencia. Promotora de Inversiones Arroba S.A. vs. Distrito Capital de Bogotá, Secretaría de Hacienda Distrital y Dirección Distrital de impuestos. 7 de marzo de 2013.

Consejo de Estado. Sentencia 19346. Proyectar Valores S.A. vs. Distrito Capital de Bogotá. 12 de diciembre de 2014.

Consejo de Estado. Sentencia 18702. Rendifin S.A. en liquidación vs. Secretaría de Hacienda - Bogotá. 27 de septiembre de 2012.

Consejo de Estado. Sentencia 18663. Seminario Consular de Bogotá. 12 de septiembre de 2013.

Consejo de Estado. Sentencia C.E. 2013-0615. 31 de mayo de 2018.

Consejo de Estado. Sentencia 16789. Sociedad Bolívar vs. DIAN. 23 de abril de 2009.

Consejo de Estado. Sentencia 23009. Socineg S.A. vs. Secretaría de Hacienda. 18 de julio de 2018.

Consejo de Estado. Sentencia 3412. The B.F. Goodrich. 12 de 08 de 1992.

Consejo de Estado. Sentencia 17339. Valmiera Enterpreise Copr. y Cia. S. en C vs. Secretaría de Hacienda. 12 de mayo de 2010.

Consejo de Estado. Sentencia 23907. Inversiones Valí Ltda. \& Cía. S.C.A vs. Municipio.

Consejo de Estado. Sentencia 250002327000-2008-00209-01(18750). 20 de noviembre de 2014.

Fecha de recepción: 24 de febrero de 2020.

Aprobación par 1: 21 de octubre de 2020.

Aprobación par 2: 16 de octubre de 2020. 